\title{
Reconstructing modern stalagmite growth from cave monitoring, local meteorology, and experimental measurements of dripwater films
}

Article

Accepted Version

Creative Commons: Attribution-Noncommercial-No Derivative Works 4.0

Baker, A. J., Mattey, D. P. and Baldini, J. U. L. (2014)

Reconstructing modern stalagmite growth from cave monitoring, local meteorology, and experimental measurements of dripwater films. Earth and Planetary Science Letters, 392. pp. 239-249. ISSN 0012-821X doi: https://doi.org/10.1016/j.epsl.2014.02.036 Available at https://centaur.reading.ac.uk/68568/

It is advisable to refer to the publisher's version if you intend to cite from the work. See Guidance on citing.

Published version at: http://www.sciencedirect.com/science/article/pii/S0012821X14001174

To link to this article DOI: http://dx.doi.org/10.1016/j.epsl.2014.02.036

Publisher: Elsevier

All outputs in CentAUR are protected by Intellectual Property Rights law, including copyright law. Copyright and IPR is retained by the creators or other copyright holders. Terms and conditions for use of this material are defined in the End User Agreement. 


\section{www.reading.ac.uk/centaur}

\section{CentAUR}

Central Archive at the University of Reading

Reading's research outputs online 


\title{
Reconstructing modern stalagmite growth from cave monitoring, local meteorology, and experimental measurements of dripwater films
}

\author{
Alexander J. Baker ${ }^{1,}$, David P. Mattey ${ }^{2}$, and James U. L. Baldini ${ }^{1}$ \\ ${ }^{1}$ Department of Earth Sciences, University of Durham, Science Laboratories, South Road, \\ Durham, DH1 3LE, U.K. \\ ${ }^{2}$ Department of Earth Sciences, Royal Holloway, University of London, Egham, TW20 0EX, \\ U.K. \\ *a.j.baker@durham.ac.uk
}

\begin{abstract}
Interpretations of high-resolution proxy datasets from stalagmites require support from longterm cave monitoring data and quantified changes in sample growth rate. One cave site for which the modern climate signal transfer systematics are relatively well characterised by cave monitoring is New St Michael's Cave, Gibraltar. This site provides a rare opportunity to reconstruct modern calcite growth, to link growth with the cave environment and local climate, and to test the sufficiency of existing growth rate theory on monthly to inter-annual timescales. Here, we use a numerical time-series growth rate model, driven by cave monitoring and local meteorological data, and the results of an experimental investigation into variation in dripwater film thickness as a function of stalagmite apex morphology to reconstruct the modern growth (AD 1951-2004) of 'Gib04a', a stalagmite retrieved from New St Michael's Cave. Our experimental measurements demonstrate that dripwater film thickness decreases linearly with increasing stalagmite curvature and that the presence of millimetre-scale surface microtopography reduces film thickness by an order of magnitude. We identified changes in growth laminae curvature from a Gib04a cut section to determine film thickness variability through time and combined this with estimated dripwater $\left[\mathrm{Ca}^{2+}\right]$ and cave air $p \mathrm{CO}_{2}$ seasonality to drive the model. Our reconstruction exhibits strong seasonality and tracks variability in calcite $\left[\mathrm{Sr}^{2+}\right]$, a trace metal whose incorporation into calcite is partially growth rate-controlled. Reconstructed growth also shows co-variation with seasonal changes in calcite fabric, with high growth corresponding to a greater density of calcite grain boundaries. We also link secular trends in karst recharge, film thickness and Gib04a growth, and assess the overall sensitivity of vertical growth rate to film thickness variability. This approach could be used to characterise the growth of other samples retrieved from wellmonitored cave systems and may prove particularly useful in quantifying seasonal bias in geochemical proxy datasets, facilitating greater robustness of palaeoclimate reconstructions.
\end{abstract}

Keywords: stalagmite, growth rate, analogue experiment, palaeoclimate 


\section{Introduction}

High-resolution, precisely-dated, multiproxy geochemical records of late Quaternary climate change are frequently obtained from stalagmites, particularly in low- and mid-latitude regions where few alternative proxy archives exist (Fairchild et al., 2006). Cylindrical stalagmites that have undergone uniform growth are most often sampled for such research, and many stalagmite records benefit from robust chronologies based on petrographic or geochemical annual laminae (Baker et al., 2008). The acquisition of multi-annual cave monitoring datasets is a critical prerequisite for palaeoclimate reconstruction using speleothems (e.g., Mattey et al., 2008; Spötl et al., 2005).

Existing empirical relationships between cave environmental parameters, such as cave atmosphere temperature and $p \mathrm{CO}_{2}\left(\mathrm{CO}_{2}\right.$ partial pressure), and stalagmite growth rate appear robust (Baker et al., 1998; Baldini et al., 2008; Genty et al., 2001) and recent studies have attempted to quantify the effects of cave processes, such as ventilation, on stalagmite growth and net geochemical proxy records (Sherwin and Baldini, 2011; Wong et al., 2011). Previous speleothem growth studies include modelled spatial variability based on 'snapshot' cave atmosphere $\mathrm{CO}_{2}$ concentration maps (Baldini et al., 2006b; Whitaker et al., 2009) and comparisons of modelled and actual growth rates. Such studies have compared average values (Baker and Smart, 1995), investigated the sensitivity of growth rate to cave dripwater hydrochemistry (Genty et al., 2001), and compared modelled growth with calcite grown in situ (Sherwin and Baldini, 2011). Collectively, this research provides first-order tests of our theoretical understanding of both instantaneous calcite growth rate and vertical stalagmite extension rate. Attempting to link stalagmite growth and morphology to climate variability, Kaufmann (2003) combined temperature estimates from ice core (GRIP and VOSTOK) and deep marine sediment core (SPECMAP) proxy data with approximations of glacialinterglacial precipitation and soil cover changes to drive a model of vertical stalagmite growth and equilibrium diameter, and Kaufmann and Dreybrodt (2004) adopted the inverse approach in attempting to derive climatic information from such stalagmite stratigraphies.

Understanding stalagmite growth variability is important for palaeoclimate research for various reasons. (i) Several studies (e.g., Polyak and Asmerom, 2001; Proctor et al., 2000) employed stalagmite growth rate itself as a palaeoclimate proxy and others have described seasonally variable stable isotope ratios (e.g., Johnson et al., 2006; Mattey et al., 2008) and trace element concentrations (e.g., Huang et al., 2001) in stalagmites that potentially result from cave ventilation dynamics and/or karst hydrological processes, both of which also affect stalagmite growth. (ii) High vertical extension rates are conducive to generating highresolution geochemical proxy datasets from stalagmites, yet to-date few studies have characterised stalagmite growth on intra-annual to decadal timescales and its implications for geochemical climate signal capture. (iii) Seasonal growth rate fluctuations potentially bias net proxy signals towards the season favourable to deposition (Baldini et al., 2008; Banner et al., 2007; Fairchild et al., 2006; Frisia et al., 2000; Mattey et al., 2008; Spötl et al., 2005). (iv) Growth rate variability may be related to climate signal modification by other processes, such as biomass change above the cave (e.g., Baldini et al., 2005) and surface and epikarst hydrology (Baker and Bradley, 2010; Bradley et al., 2010; Darling, 2004). Moreover, 
stalagmite growth rate may provide a proxy for surface or soil temperature (Genty et al., 2001), rainfall amount (Genty and Quinif, 1996), or vegetation changes (Baldini et al., 2005). The work of Kaufmann (2003) and Kaufmann and Dreybrodt (2004) represents an important advance in linking stalagmite growth with climate variability, but the model resolutions used (1000 and 200 years, respectively) are too low to be directly applicable to many highresolution palaeoclimate studies using stalagmites.

The principal non-biological controls on calcareous speleothem deposition (temperature, drip rate, dripwater $\left[\mathrm{Ca}^{2+}\right]$, and soil and cave air $p \mathrm{CO}_{2}$ ) are relatively well understood (Dreybrodt, 1999; Genty et al., 2001). Recent research has characterised their spatio-temporal variability at certain sites (Banner et al., 2007; Whitaker et al., 2009) and, in particular, highlighted the importance of cave atmosphere $p \mathrm{CO}_{2}$ dynamics for speleothem palaeoclimatology (Baldini et al., 2008; Fairchild et al., 2006). Although interpreting climatic variability from stalagmite morphology alone is challenging (Dreybrodt, 1988), understanding the physical controls on stalagmite growth, such as drop volume and dripwater film thickness, is necessary for proper linkage of local climate variability, cave environment systematics, and stalagmite growth behaviour.

The following equation describes vertical stalagmite extension rate $\left(R_{0}\right)$ fed by a punctiform drip source theoretically (Baker et al., 1998; Baldini et al., 2008; Buhmann and Dreybrodt, 1985; Dreybrodt, 1980; 1999):

$R_{0}=1174\left(\left[\mathrm{Ca}^{2+}\right]-\left[\mathrm{Ca}^{2+}\right]_{a p p}\right)\left(\delta \mathrm{t}^{-1}\right)\left(1-e^{-\alpha \mathrm{t} \delta^{-1}}\right)$

(Equation 1)

where the constant 1174 converts molecular accumulation rate of calcite $\left(\mathrm{mmol} \mathrm{mm}^{-1} \mathrm{~s}^{-1}\right)$ to vertical extension rate $\left(\mathrm{mm} \mathrm{a}^{-1}\right) ;\left[\mathrm{Ca}^{2+}\right]$ is the initial calcium cation concentration of the dripwater $\left(\mathrm{mmol} \mathrm{L}^{-1}\right) ;\left[\mathrm{Ca}^{2+}\right]_{a p p}$ is the apparent dripwater $\left[\mathrm{Ca}^{2+}\right]\left(\mathrm{mmol} \mathrm{L}^{-1}\right)$ after equilibration with a given cave atmospheric $p \mathrm{CO}_{2} ; \delta$ is the dripwater film thickness $(\mathrm{mm})$ from which calcite precipitates according to $\mathrm{Ca}^{2+}(a q)+2 \mathrm{HCO}_{3}^{-}(a q) \leftrightarrow \mathrm{CaCO}_{3(s)}+\mathrm{CO}_{2(g)}+\mathrm{H}_{2} \mathrm{O}_{(l)}$; $\mathrm{t}$ is the drip interval (s); and $\alpha$ is a 'kinetic constant' $\left(\mathrm{mm} \mathrm{s}^{-1}\right)$ that is sensitive to change in $\delta$ and ambient cave temperature. Note that $R_{0}$ may also be denoted ' $W_{0}$ ' (e.g., by Kaufmann, 2003). This equation was tested by Sherwin and Baldini (2011), who found close agreement between measured in situ calcite deposition and a model estimate. However, the main source of uncertainty encountered in this study was in estimating $\delta$, highlighting the need to constrain this parameter before any time-series reconstruction of stalagmite growth may be attempted. Of particular interest is whether $\delta$ tends to remain constant or varies significantly with time, according to relationships with other variables.

In this paper, the 51-year growth of a modern stalagmite ('Gib04a') retrieved from New St Michael's (NSM) Cave, Gibraltar (Mattey et al., 2008), is reconstructed in an a priori forward model driven by cave monitoring (cave atmosphere $p \mathrm{CO}_{2}$ and temperature and drip discharge) and local meteorological (surface temperature, rainfall, and water excess) time series datasets. Additionally, this model is refined with experimental measurements of dripwater films, which provide basic constraints on the role of film thickness on growth rate. Our rationale for selecting Gib04a as a target specimen is as follows. (i) Cave monitoring 
data (continuous logging and spot measurements) are available since 2004 (Mattey et al., 2008) and modern climate signal transfer systematics have been relatively well constrained at NSM Cave by Mattey et al. (2010). (ii) Continuous monthly meteorological time series datasets (surface air temperature and precipitation) are available from the nearby Royal Air Force Meteorological Office (RAFMO) station, which is also the site of Global Network for Isotopes in Precipitation (GNIP) sampling since 1962 (Fig. 1), with a temporal coverage appropriate to drive the time series growth model. (iii) Gib04a underwent relatively fast vertical extension $\left(\sim 0.9 \mathrm{~mm} \mathrm{a}^{-1}\right)$ and exhibits annual petrographic laminae, providing a robust age model, which is substantiated by annual carbon isotope cyclicity and correct identification of the atmospheric ${ }^{14} \mathrm{C}$ activity 'bomb spike' (Mattey et al., 2008). Altogether, these factors provide a rare opportunity to $(i)$ develop, to our knowledge, the first time-series growth reconstruction for a modern speleothem and (ii) test the sufficiency of existing growth rate theory (as a natural system description) in capturing seasonal and interannual variation. To conclude, the implications for linking stalagmite growth and local climate are considered.

\section{Site description}

NSM Cave developed within the dolomitised Gibraltar Limestone Formation of the Rock of Gibraltar (Gibraltar peninsula, southern Iberia; $36^{\circ} 9^{\prime} \mathrm{N}, 5^{\circ} 21^{`} \mathrm{~W}$ ), whose maximum elevation is $426 \mathrm{~m}$ above mean sea level (Fig. 1). Pervasive fracturing provides extensive macroporosity, and drips sites within NSM Cave are fed by down-dip and sub-vertical fracture systems. NSM Cave is at least Pleistocene in age (Rodríguez-Vidal et al., 2004), phreatic in origin, has experienced uplift of $\sim 275 \mathrm{~m}$, and preserves evidence for multiple phases of drainage and secondary speleothem decoration (Tratman, 1971). NSM Cave has no known natural entrances; however, a $1 \mathrm{~m}^{2}$ trap door, constructed in 1942 and the only link with Old St Michael's Cave, does not significantly disturb the natural chimney-effect ventilation (Mattey et al., 2010; 2008 and references therein).

Mattey et al. (2010) identified links between ventilation dynamics, calcite fabrics, stable isotope ratio and trace element seasonality, and dripwater trace element variability. Seasonal ventilation of NSM Cave is characterised by rapid summer-to-winter increases and winter-tosummer decreases in cave atmosphere $p \mathrm{CO}_{2}$, between near-atmospheric values and 3000 8000 ppm, occurring over several days. Ventilation of this cave system is the focus of ongoing research and therefore a full explication of ventilation processes and controls on cave air $p \mathrm{CO}_{2}$ variability is beyond the scope of this paper. Here, we make reasonable simplifications in light of this on-going work, which are explained in the following section. Mattey et al. (2010) also compared drip discharge and hydrologically-effective precipitation data and performed groundwater dye tracer experimentation, suggesting that coherence in dripwater hydrochemistry between separate monitoring sites results from common hydrochemical control, given the observed distinct recharge responses and inferred epikarst flow paths for each drip site. 


\section{Methods}

\subsection{Experimental measurements of dripwater film thickness}

Collister and Mattey (2008) determined an empirical relationship between stalactite radius and drop volume experimentally using analogue materials, constraining a previously poorly understood parameter impacting stalagmite width. Hansen et al. (2013) determined time constants for $\mathrm{CO}_{2}$ degassing, new $p \mathrm{CO}_{2}$ equilibration, and calcite precipitation using experimental analogue materials, demonstrating that the geochemical evolution of cave dripwater is a function of these constants, not simply of $\mathrm{CO}_{2}$ degassing rate. This experimental literature has implications for cave monitoring and speleothem sampling strategies. However, the role of stalagmite morphology on vertical extension is yet to be quantified empirically.

We determined the dependency of dripwater film thickness $(\delta)$ on stalagmite curvature and surface microtopography using 10 plano-convex Al domes (uniform spherical curvature), and employed image analysis techniques to calculate the thickness of water films formed from a known volume of water dispensed from a known height. In geometric terms, the domes utilised for these experimental measurements are chords of spheres of various known radii. The curved surface area, $A$, of each dome is given by:

$$
A=2 \pi \rho^{2}\left(1-\sqrt{1-\frac{x^{2}}{\rho^{2}}}\right)
$$

(Equation 2)

where $\rho$ is the spherical radius and $x$ is the projected radius of the base of the subtended cone of the chord (i.e., the radius of the circular base of the dome). As $x \rightarrow \rho, A \approx 2 \pi \rho^{2}$ (i.e., the area of a hemisphere). $A$ is expressed here in terms of projected radius because this parameter is known for all domes. (Alternatively, $A$ may be expressed more simply in terms of arc length, but use of Eq. 2 favourably avoids the need for additional measurements of arc length and propagating their associated error to the final $\delta$ calculations.)

Each dome was wetted and an $80 \mu \mathrm{l}$ droplet dispensed onto its apex using a calibrated mechanical pipette, allowed to spread, and photographed. The position of domes in each image and the viewshed of the camera were fixed (Fig. S1). Droplets were dyed in order to create a colour contrast between the droplet and the dome in the image (Fig. S2). For each image, the Java ${ }^{\mathrm{TM}}$-based, public domain software ImageJ (Schneider et al., 2012) was used to threshold the colour of the dyed water film from that of the surface of the dome (Fig. S2) and a particle analysis tool was used to determine the projected area (2-D) of the dripwater film, which was corrected for dome curvature using Eq. 2. Water droplets were dispensed from a height of $10 \mathrm{~mm}$ to prevent splashing and conform to experimental conditions, but this is less than 'typical' drop heights at natural drip sites (see Supplementary Material). Five replicates were performed for each dome (Fig. 4a).

Simplistically, calculating $\delta$ assumes that a droplet spreads radially from the dome's apex, forming a uniform disc of curvature equal to $\rho$. However, because many photographed droplets exhibited non-circular forms (Fig. S2), it is necessary to avoid this simplification by 
calculating the (curved) surface area of each dome and the precise proportion covered by the $80 \mu$ droplet. $\delta$ is given by:

$\delta=\frac{v}{A_{\mathrm{d}}}$

(Equation 3)

where $v$ is droplet volume $\left(\mathrm{mm}^{3}\right)$ and $A_{\mathrm{d}}$ is the curved surface area of the dripwater film at rest on the dome $\left(\mathrm{mm}^{2}\right)$. Using a high-precision balance, we estimated the error associated with $v$ to be of the order of $0.01 \%$.

We performed a second set of measurements with non-smooth domes, created by affixing a layer of laboratory-grade quartzose sand (pre-filtered through a $0.15-0.425 \mathrm{~mm}$ particle mesh) to the surface each dome. The grain size is comparable to previous estimates of $\delta$ by Dreybrodt (1981) and acts as an opposite end-member to the idealised, smooth surfaces. We favour this analogue for stalagmite surface microtopography because it preserves the original curvature of each dome, thus isolating the microtopography effect. A second set of $\delta$ calculations was performed. Greater scatter was found for these measurements, so Fig. 4b shows mean values with 1 standard deviation.

This approach incurs two important uncertainties. (i) The interfacial properties and contact angles associated with water, air and dry $\mathrm{Al}$ are different from those associated with water, air and dry calcite, potentially giving rise to erroneous results. Dripwater films would be thickest at a dome's apex if dispensed onto a dry dome, so wetted dome surfaces were used to better approximate the interfacial properties of a natural speleothem substrate. Additionally, we duplicated measurements on Al (with $\rho=\infty$ ) using wetted calcite spar, a precaution undertaken by Collister and Mattey (2008). (ii) In this study, the magnitudes of drop height and microtopography are constants. Therefore, future experimental work should attempt to quantify the role of variable drop height and degree of microtopography on film thickness.

\subsection{Construction of a time series stalagmite growth model}

We derived transfer functions to estimate $\left[\mathrm{Ca}^{2+}\right]_{a p p}$ and $\alpha$, both of which are based on earlier calculations by Dreybrodt (1999), to provide inputs for Eq. 1. A non-linear relationship between cave atmosphere $p \mathrm{CO}_{2}$ and $\left[\mathrm{Ca}^{2+}\right]_{a p p}$ was determined for a constant temperature of $20{ }^{\circ} \mathrm{C}$ (Fig. 2a) and a linear relationship between temperature and $\left[\mathrm{Ca}^{2+}\right]_{a p p}$ was determined for a constant $\mathrm{pCO}_{2}$ of $2000 \mathrm{ppm}$ (Fig. 2b). Combining these relationships gives the following transfer function:

$\left[\mathrm{Ca}^{2+}\right]_{a p p}=\frac{1}{2}\left(\left(5.872 p \mathrm{CO}_{2}^{0.2526}\right)+\left(-0.0167 \mathrm{~T}_{\mathrm{c}}+1.5146\right)\right)$

(Equation 4)

where $p \mathrm{CO}_{2}$ is that of cave air (atm) and $\mathrm{T}_{\mathrm{c}}$ is in-cave temperature $\left({ }^{\circ} \mathrm{C}\right)$.

A non-linear relationship between $\alpha$ and $\mathrm{T}_{\mathrm{c}}$ was determined for several values of $\delta$. Selecting a single value is not necessary because our experimental measurements provide independent constraints on $\delta$ (Fig. 2c) and $\alpha$ depends only on $\mathrm{T}_{\mathrm{c}}$ for $\delta<0.4 \mathrm{~mm}$ (Baker et al., 1998; 
Hansen et al., 2013). A non-linear relationship between $\alpha$ and $\delta$ was determined for a constant temperature of $20^{\circ} \mathrm{C}$ (Fig. 2d). Combining these gives the following transfer function:

$$
\alpha=\frac{1}{2}\left(\left(2.22 \times 10^{-7} \mathrm{~T}_{\mathrm{c}}^{2}+6.36 \times 10^{-6} \mathrm{~T}_{\mathrm{c}}+3.88 \times 10^{-5}\right)+\left(-0.0057 \delta^{2}+0.002 \delta+0.0001\right)\right)
$$

(Equation 5)

The constant values for which Eq. 4 and Eq. 5 were derived are those of Dreybrodt (1999) which best represent conditions at the Gib04a site since cave monitoring began. Mean annual cave air $p \mathrm{CO}_{2}$ is $2496 \mathrm{ppm}$ and $\mathrm{T}_{\mathrm{c}}$ remains constant at $17.9^{\circ} \mathrm{C}$ at the Gib04a drip site (Fig. 3), which is satisfactorily close to the temperature for which the relationships in Fig. 2a and Fig. 2 d were derived. Therefore, Eq. 4 and Eq. 5 are used with minimal systematic error and $\alpha$ varies with $\delta$, rather than assuming a constant value for the entire reconstruction.

Finally, an input time series of dripwater $\left[\mathrm{Ca}^{2+}\right]$ is required for Eq. 1. Dripwater $\left[\mathrm{Ca}^{2+}\right]$ measured at the Gib04a site likely equilibrated with soil $p \mathrm{CO}_{2}$ of $\sim 1 \%$ (Mattey et al., 2010). Unfortunately, there is no overlap between on-going monitoring at NSM Cave and the period of modern Gib04a growth (1951-2004). To compensate for this, we linked between dripwater $\left[\mathrm{Ca}^{2+}\right]$ and surface environmental parameters. Genty et al. (2001) derived an empirical relationship between mean annual cave temperature and dripwater $\left[\mathrm{Ca}^{2+}\right]$ based on data from temperate European sites. Although this is a useful relationship, it is not appropriate to use temperature as a single predictor for dripwater $\left[\mathrm{Ca}^{2+}\right]$ at NSM Cave, despite the similarity between mean annual surface and cave temperatures (18.3 and $17.9^{\circ} \mathrm{C}$, respectively). In a Mediterranean climate, with relatively distinct dry and rainy seasons, moisture availability as well as surface temperature control soil $\mathrm{CO}_{2}$ productivity (Baldini et al., 2008; Murthy et al., 2003). Measured dripwater $\left[\mathrm{Ca}^{2+}\right]$ at the Gib04a site is highest in winter, suggesting a potential connection to moisture availability, and other Mediterranean sites (e.g., Clamouse Cave, southern France) do not plot along the Genty et al. (2001) relationship. Given these observations, we performed multivariate regression between NSM Cave dripwater $\left[\mathrm{Ca}^{2+}\right]$ (Mattey et al., 2010) and surface environmental (predictor) variables (temperature, rainfall and potential evapotranspiration) for Gibraltar, obtaining the following expression:

$\left[\mathrm{Ca}^{2+}\right]=\frac{123-3.45 \mathrm{~T}_{\mathrm{s}}-0.0139(\mathrm{P}-\mathrm{E})}{40.078}$

(Equation 6)

where $\mathrm{P}$ is total monthly precipitation and $\mathrm{E}$ is potential evapotranspiration (Fig. 3), calculated according to the method of Thornthwaite (1948). Dividing by the molecular mass of $\mathrm{Ca}$ (40.078) converts $\left[\mathrm{Ca}^{2+}\right]$ from ppm to mmol $\mathrm{L}^{-1}$. Combined, $\mathrm{T}_{\mathrm{s}}$ and epikarst recharge explain $67 \%$ of $\left[\mathrm{Ca}^{2+}\right]$ dripwater variability observed at the Gib04a site, with $0.23 \mathrm{mmol} \mathrm{L}{ }^{-1}$ uncertainty. 


\section{Results and discussion}

\subsection{Relationships between local meteorological variables, cave microclimate, and stalagmite growth}

Gibraltar's Mediterranean maritime climate is characterised by mean summer (June-August) and winter (December-February) temperatures of 22.8 and $13.2{ }^{\circ} \mathrm{C}$, respectively, with $\sim 0.7$ ${ }^{\circ} \mathrm{C}$ warming over the last $\sim 30$ years (Wheeler, 2011), and mean summer (April-September) and winter (October-March) total precipitation of 135 and $668 \mathrm{~mm}$, respectively, with a 20 mm decrease mean annual rainfall since 1960 (IAEA/WMO, 2013; Wheeler, 2006; 2007). Clear seasonality in NSM Cave microclimate exists. Winter months produce seasonally low temperature, high water excess, high cave atmosphere $p \mathrm{CO}_{2}$, and low dripwater $\left[\mathrm{Ca}^{2+}\right]$. The opposite is therefore true of each during summer months. Dripwater $\left[\mathrm{Ca}^{2+}\right]$ is not exactly inphase with surface temperature because it depends also on water excess, which is sensible given that existing monitoring data from NSM Cave and from the overlying soil cover show that cave air $p \mathrm{CO}_{2}$ seasonality is not in exact phase with soil moisture availability (i.e., rainfall seasonality). Predictable $p \mathrm{CO}_{2}$ seasonality at the Gib04a site co-varies with modelled dripwater $\left[\mathrm{Ca}^{2+}\right]$ because both are primarily temperature-dependent (Fig. 3). Ventilation of NSM Cave is probably venturi- and/or chimney-type (Mattey et al., 2010) and the subject of on-going research. These monitoring data are discussed in much greater detail by Mattey et al. (2010) and indicate fast growth of Gib04a, whose actual mean linear extension rate was $\sim 0.9 \mathrm{~mm} \mathrm{a}^{-1}$ during 1951-2004 (Mattey et al., 2008).

\subsection{Control of stalagmite apex morphology on film thickness}

Dreybrodt (1988) estimated $\delta$ to be in the range $0.05-0.4 \mathrm{~mm}$, yet microtopography is not parameterised explicitly in growth models. Baldini et al. (2008) found that $\delta$ may tend towards the upper end of that range $(0.32 \mathrm{~mm})$ for a stalagmite exhibiting mm-scale surface microtopography, consistent with the measurements of Baker et al. (1998), but Kaufmann (2003) fixed $\delta$ at $10^{-4} \mathrm{~mm}$. Therefore, few constraints on $\delta$ exist. We derived two empirical $\delta$ $\rho$ relationships for smooth and microtopographical surfaces (Fig. 4, Table S1), providing experimental constraints. Both relationships are linear and negatively correlated. For smooth surfaces, $\delta$ decreases with increasing curvature $\left(r^{2}=0.74\right)$ because droplets spread under gravity and are retarded only by surface tension effects. Over microtopography $\left(r^{2}=0.47\right)$, spreading is greatly encouraged by capillary action and reduced surface tension. Importantly, microtopography $(0.15-0.425 \mathrm{~mm})$ reduces film thickness by an order of magnitude compared to idealised, smooth substrates, and our values are consistent with those of Baker et al. (1998). These results indicate that stalagmites with irregular morphologies or high surface roughness are less likely to undergo fast vertical extension conducive to generating highresolution palaeoclimate records.

For flat surfaces $(\rho=\infty)$, mean $\delta$ values for smooth and non-smooth surfaces are similar: 0.93 and $0.77 \mathrm{~mm}$, respectively, indicating flat surfaces behave differently from curved surfaces. Spreading over a smooth surface under gravity or by capillary action over a 
microtopographical surface is reduced if that surface is flat, and the effect of microtopography to encourage spreading is significantly reduced. For comparison, additional measurements were performed on wetted calcite spar with $\rho=\infty$, providing natural interfacial properties between calcite, water and air. Mean $\delta$ for flat calcite is $0.83 \mathrm{~mm}$, which is similar to values for wetted Al (Fig. 4). These observations are important because many activelygrowing stalagmites selected for research, including Gib04a, exhibit uniform cylindrical morphology and possess low-curvature apexes, particularly if initial surfaces are near-flat (Dreybrodt, 1999). We speculate that water spreading over curved microtopographical surfaces is reduced by the development of minute menisci over the substrate (i.e., between sand grains in our analogue), but this is less significant for stalagmites exhibiting undulatory rather than granular microtopography.

For low-curvature smooth surfaces $(\rho>75 \mathrm{~mm})$, our empirically-derived $\delta$ values overestimate those of Dreybrodt (1999) and Hansen et al. (2013), highlighting the role of other mechanical processes affecting the amount of dripwater at rest on a stalagmite surface and therefore $\delta$. Under experimental conditions, water dispensation onto Al and calcite spar involves no water loss through mechanical processes, such as splashing. In natural cave settings, with greater drop heights, the net effect of splashing is a reduction of $\delta$, and potentially results in unconventional growth features, such as splash coronae, where maximum calcite accumulation occurs away from the vertical extension axis. Potentially, a relationship between drip height and amount of water lost by mechanical processes for a given droplet volume, which depends on stalactite radius and ambient barometric pressure (Collister and Mattey, 2008), may be demonstrable. Quantifying this and the role of different types and magnitudes of microtopography will provide future modelling challenges.

In summary, our data show a linear decrease in film thickness with increasing surface curvature and that the presence of sub-millimetre scale microtopography reduces $\delta$ by an order of magnitude, providing constraints on temporal $\delta$ variation in Gib04a, which is discussed in the following section.

\subsection{Constraints on film thickness and reconstructing modern Gib04a growth (1951- 2004)}

We estimated the average curvature of 11 visible growth laminae in Gib04a (Fig. 5) and calculated the associated $\delta$ values for each using our empirical relationships (Fig. 4, Table 1). Excepting laminae 2 and 3 , a decreasing trend in $\delta$ is found with decreasing equilibrium diameter of Gib04a during the period 1951-2004, showing broadly uniform stalagmite growth (Fig. 5). Broadly, these $\delta$ estimates for Gib04a are within the range described by previous research (Dreybrodt, 1999; Kaufmann, 2003), though they tend towards higher values of that range during the early phase of Gib04a growth. We have not estimated $\delta$ for every macroscopic growth lamina in Gib04a, aiming instead to identify locations at an approximately regular interval where curvature changes notably. In the Gib04a $R_{0}$ reconstruction, each value of $\delta$ is 'active' until the subsequent identified surface (Table 1). 
The full Gib04a $R_{0}$ reconstruction shows clear seasonality (Fig. 6, Table S2) that is related to dependence on surface temperature, water excess, and cave atmosphere $p \mathrm{CO}_{2}$. Total modelled vertical extension is $55.99 \mathrm{~mm}$, which overestimates Gib04a's actual growth by $8.16 \mathrm{~mm}$. Overall, model performance demonstrates that existing growth rate theory sufficiently describes Gib04a growth on seasonal to interannual timescales. However, an overestimation of calcite growth was also observed by Day and Henderson (2013). These intriguing deviations from existing theory warrant the application of our modelling approach to other well-monitored cave sites, given that local meteorological data (surface temperature and water excess) provide constraints on dripwater $\left[\mathrm{Ca}^{2+}\right]$ using Eq. 6 or previous work by Genty et al. (2001) for semi-arid or temperate environmental settings, respectively.

\subsubsection{Non-uniform Gib04a growth}

Growth laminae 2 and 3 in Gib04a (Fig. 5) represent the development of a splash corona; during this interval, calcite precipitation has occurred away from the central growth axis. PreHolocene Gib04a growth provided a low-curvature lower edifice above which modern growth initiated (Fig. 5). Therefore, the development of this feature is unexpected, given the results of Dreybrodt (1999). Nevertheless, if non-uniform growth and the development of the splash corona began close to lamina 1 , the estimated $\delta$ value for this initial surface may be an overestimate. Additionally, this suggests that shifts in the position of the vertical extension axis occurred, potentially explaining the $\sim 8 \mathrm{~mm}$ model overestimation. At their intersection with the vertical growth axis, lamina 2 is inclined and lamina 3 is near-flat, and several laminae immediately below and above lamina 3 exhibit convex (i.e., negative) curvature. Additionally, several laminae exhibit relatively sharp inflections in $\rho$ (Fig. 5), though these do not affect the curvature uniformity of calcite deposited immediately above them, and only one such inflection is proximal to the vertical growth axis. Such observations may be difficult to make in 2-D sections of slower-growing stalagmites. Our empirical relationships give realistic $\delta$ estimates for negative $\rho$ values, but their physical plausibility is uncertain. The $\delta$ values for laminae 2 and 3 plot away from the linearly decreasing $\delta$ trend and several indistinct or discontinuous laminae are apparent (Fig. 5), both of which produce a period of low vertical extension and reduced seasonal variability (Fig. 6). This non-uniform growth, totalling $\sim 6 \mathrm{~mm}$, persisted for $\sim 10$ years.

Alternatively, a decrease in calcite saturation index, related to surface temperature changes, or to changes in drip rate or dry season deposition, may have caused this temporary change in calcite distribution. However, our growth reconstruction and temperature data do not support this explanations (see section 4.5) and there is no evidence for decreased dripwater $\left[\mathrm{Ca}^{2+}\right]$ saturation in the past (e.g., reduce soil/vegetation cover). Additionally, calcite precipitation may still occur at the point where water droplets impact a stalagmite (Hansen et al., 2013), but the distribution of calcite precipitation over pre-existing laminae is affected by splashing. Vertical calcite accumulation at the central growth axis is reduced by the development of splash coronae, partly as a result of a reduction in $\delta$. 


\subsection{Model validation: comparing growth seasonality with Gib04a petrography and $\mathrm{Sr}$}

Stalagmite $R_{0}$, calcite microfabric and $\mathrm{Sr}$ concentrations may be linked because $\mathrm{Sr}$ incorporation into calcite is partially dependent on $R_{0}$ (Fairchild and Baker, 2012). At low instantaneous growth rates, $\mathrm{Sr}$ may substitute for $\mathrm{Ca}$ in the calcite lattice, but is susceptible to competition with other species such as $\mathrm{Mg}$ and $\mathrm{Na}$ (Boch, 2008; Fairchild et al., 2001) and incorporation of organic macromolecules (McGarry and Baker, 2000). At higher rates, Sr occupies interstitial and defect lattice sites, the abundance of which increases with $R_{0}$ (Boch, 2008 ), because the lattice is less able to distinguish between $\mathrm{Ca}^{2+}$ (ionic radius $=1.08 \AA$ ) and larger divalent trace metals, such as $\mathrm{Sr}^{2+}(1.44 \AA$ ) (Gabitov and Watson, 2006; Huang and Fairchild, 2001; Lorens, 1981). Therefore, $R_{0}$ and the effective partition coefficient for $\mathrm{Sr}$ in calcite $\left(\mathrm{K}_{\mathrm{d}}^{\mathrm{Sr}}\right)$ may co-vary (Fairchild and Treble, 2009; Gabitov et al., 2014; Gabitov and Watson, 2006). Boch (2008) reported higher Sr and vertical extension rate associated with porous laminae (summer deposition) in stalagmites sampled from Katerloch Cave, southeast Austria. However, Borsato et al. (2007) found no ostensible seasonal co-variation between trace element concentrations and calcite fabric in a stalagmite from Grotta di Ernesto, northeast Italy, but $\mathrm{Sr}$ maxima increased linearly with growth. Experimental evidence indicates $R_{0}$ and $\mathrm{Sr}$ incorporation are strongly related above $R_{0} \approx 0.5 \mathrm{~mm} \mathrm{a}^{-1}$ (Gabitov and Watson, 2006), but there is also evidence that $R_{0}$ increases well above the natural range are required to produce such co-variation (Day and Henderson, 2013). These results suggest that links between growth mechanics and $\mathrm{Sr}$ variability may vary temporally or from site to site. For NSM cave, several observations indicate that $\mathrm{K}_{\mathrm{d}}^{\mathrm{Sr}}$ should respond to Gib04a $R_{0}$ : $(i)$ modelled Gib04a $R_{0}$ falls only occasionally below $0.5 \mathrm{~mm} \mathrm{a}^{-1}$, most notably between 1956 and 1965 (Fig. 6), (ii) Gib04a site temperature remained constant over the monitored period (Fig. 3), and (iii) soil cover above NSM Cave is minimal, so competition between $\mathrm{Sr}$ incorporation and molecular organic matter deposition in speleothem calcite is less a factor compared with other sites. Therefore, comparing our $R_{0}$ reconstruction with high-resolution synchrotron $\mu$ XRF Sr data, available for the upper $\sim 13 \mathrm{~mm}$ (corresponding to 1987-2004) of Gib04a (Mattey et al., 2010) provides a critical test of the reconstruction's fidelity.

The $R_{0}$ reconstruction tracks Gib04a Sr concentrations closely, capturing the seasonal and, occasionally, the sub-seasonal variability (Fig. 6). Therefore, $R_{0}, \mathrm{Sr}$ and calcite fabrics can be compared with confidence, and across the most recent $\sim 4 \mathrm{~mm}$ the discrepancy between actual and modelled vertical extension is $0.18 \mathrm{~mm}$ (Fig. 7). Gib04a exhibits annual couplets of pale columnar calcite and darker compact calcite (Fig. 7a), which represent winter and summer deposition, respectively (Mattey et al., 2010). Dark compact calcite is characterised by a greater density of calcite grain boundaries (Fig. 7b), and this associated with high summer $\mathrm{Sr}$ and $R_{0}$, although this is less clear for 2000-1 (Fig. 7c, d). This suggests that Gib04a calcite lattice changes with increased linear extension rate appear to favour $\mathrm{Sr}$ incorporation, consistent with experimental data (e.g., Gabitov et al., 2014). The amplitudes of seasonal $R_{0}$ and $\mathrm{Sr}$ variations match well, though higher frequency variability indicates non- $R_{0}$ effects inhibit Sr incorporation. A potential microhiatus in Gib04a growth was identified by Mattey et al. (2010) at 2001-2, which is characterised by an abrupt change in the density of calcite grain boundaries (Fig. 7b), indicating that the year-to-year deposition of calcite couplets is 
not regular. These abrupt changes in calcite fabric are likely due to ventilation dynamics at NSM Cave. Rapid summer-to-winter increases in cave atmosphere $p \mathrm{CO}_{2}$ from near atmospheric values occur (Fig. 3), potentially leading to weekly-to-monthly scale cessation of calcite deposition. However, this is not apparent in reconstructed $R_{0}, \mathrm{Sr}$ or other previouslypublished trace element data from Gib04a. Dripwater $\left[\mathrm{Ca}^{2+}\right]$ is sufficient to maintain vertical extension at lower than average rates $\sim 0.5 \mathrm{~mm} \mathrm{a}^{-1}$, through winters when cave air $p \mathrm{CO}_{2}$ is high.

Ionic competition affects $\mathrm{Sr}$ incorporation, implying that the $\mathrm{K}_{\mathrm{d}}^{\mathrm{Sr}}-R_{\mathrm{o}}$ relationship may vary temporally, responding to changes in ionic supply. Despite $R_{0}$-Sr co-variation apparent in Gib04a, it is necessary to estimate $\mathrm{Sr}$ incorporation. Unfortunately, the available dripwater hydrochemistry and Gib04a trace element time series datasets do not overlap, but we compensate for this by calculating $\mathrm{K}_{\mathrm{d}}^{\mathrm{Sr}}$ based on an extrapolation of the $R_{0}$ reconstruction (see Supplementary Material). Mean $R_{0}$-derived $\mathrm{K}_{\mathrm{d}}^{\mathrm{Sr}}$ is 0.39 (Fig. S3), which is above but close to the published range of experimentally-determined and natural speleothem values (Day and Henderson, 2013; Fairchild and Baker, 2012; Gabitov and Watson, 2006), supporting the fidelity of the $R_{0}-\mathrm{Sr}$ comparison.

\subsection{Inter-annual growth rate variability}

A first order sensitivity analysis suggests that $R_{0}$ is sensitive to $\delta$ variability (see Supplementary Material and Fig. S4). Inter-annual morphological change in modern Gib04a growth is characterised by decreasing equilibrium diameter and increasing $\rho$, resulting in a decreasing $\delta$ trend (Fig. 5). Consequently, $\alpha$ also decreases during the period 1951-2004 according to Eq. 5. The secular decrease in $R_{\mathrm{o}}$ (Fig. 8), most obviously after the non-uniform growth period, potentially reflects drying in Gibraltar. Stalagmite equilibrium diameter can reflect long term trends in karst aquifer recharge (and therefore rainfall). An overall $\sim 30 \mathrm{~mm}$ decline in mean annual rainfall and increasing $\mathrm{T}_{\mathrm{S}}$ since 1973 result in a linear decrease in total annual water excess feeding Gib04a (Fig. 8). (Note that 1996/1997 winter rainfall is anomalous.) Qualitatively, the tapered shape of Gib04a may be explained in this way. Decreasing Gib04a equilibrium diameter and increasing $\rho$ (Fig. 5) cause decreases in other growth-determining parameters ( $\delta$ and $\alpha$ ) and result in a secular decline in $R_{0}$ since 1965, providing a first-order link between Gibraltar climate and Gib04a's growth history. Interestingly, step-like decreases in $R_{0}$ during the non-uniform growth period and during 1990-1994 coincide with large temperature fluctuations, but secular temperature changes do not correlate with $R_{0}$ (Fig. 8). Cave air $p \mathrm{CO}_{2}$ seasonality, which is effectively invariant, also cannot explain this, indicating that the dominant control on long-term changes in vertical extension and morphology of Gib04a is karst recharge. 


\section{Conclusions}

This paper presents $(i)$ experimental measurements of dripwater film thickness performed on analogue materials, which are used to model $\delta$ variation during modern Gib04a growth (1951-2004), and (ii) the first attempt to reconstruct temporal vertical growth rate variability in a modern stalagmite. Our experimental measurements demonstrate that $\delta$ decreases linearly with increasing surface curvature and that the presence of sub-millimetre scale microtopography reduces $\delta$ by an order of magnitude compared to idealised, smooth surfaces (Fig. 4). We attribute these observations to spreading under gravity and by capillary action versus surface tension effects. By examining changes in growth laminae curvature, we identified a linearly decreasing $\delta$ trend in the Gib04a stalagmite (Fig. 5), consistent with its uniform tapered morphology (decreasing equilibrium diameter and increasing curvature). A period of non-uniform growth, with two $\delta$ outliers resulting from the development of a splash corona, occurs during 1956-1965 (comprising $\sim 6 \mathrm{~mm}$ vertical extension). Furthermore, a first-order $\delta$-sensitivity analysis of $R_{0}$ (using only weighted mean $\delta$ and $\alpha$ values) demonstrates that Gib04a's total vertical growth is underestimated by an order of magnitude and non-sensible negative $R_{0}$ values arise if $\delta$ variability is not taken into account.

The Gib04a growth reconstruction, based on cave monitoring, meteorological data, captures growth seasonality but overestimates total vertical accumulation by $\sim 8 \mathrm{~mm}$. Seasonality in surface temperature, hydrologically effective precipitation (both of which control dripwater $\left[\mathrm{Ca}^{2+}\right]$ ), cave atmosphere $p \mathrm{CO}_{2}$, and moderate seasonality in drip interval, at NSM Cave (Fig. 3 ) forces strongly seasonal growth of Gib04a (Fig. 5 and Fig. 6). Seasonality in $R_{0}$ co-varies with high-resolution Sr concentration data (Fig. 6) and Sr partitioning between dripwater and calcite is captured reasonably by the reconstruction (Fig. S3). A high-resolution comparison of $R_{0}$ with $\mathrm{Sr}$ and changes in grain-scale calcite fabric across the upper $\sim 4 \mathrm{~mm}$ shows that the amplitude of seasonal $R_{0}$ and $\mathrm{Sr}$ variation is comparable, and both are associated with subannual layers of dense calcite grain boundaries (Fig. 7). An inter-annual decrease in reconstructed Gib04a $R_{0}$ is likely linked to a similar decrease in rainfall in Gibraltar since 1960 and this is explained by secular decreases in $\delta$ and equilibrium diameter of Gib04a. Therefore, our results demonstrate that growth rate theory is sufficient on inter- and intraannual timescales, but represent not the first example of overestimating vertical extension rate. Future work should therefore apply our approach to other well-monitored cave systems to determine whether modifications of growth rate theory are necessary in particular environmental settings.

Recent research has indicated that $(i)$ seasonal dripwater trace element hydrochemistry, if recorded by stalagmites, may provide geochemical markers of seasonal growth laminae (Fairchild and Treble, 2009; Wong et al., 2011), and (ii) $\delta$ controls the time constant for $\mathrm{CO}_{2}$ degassing (Hansen et al., 2013). In light of these results, our empirical constraints on the relationship between $\delta$ and stalagmite morphology and $R_{0}$ modelling results provide a timely test of stalagmite growth rate theory. Immediate experimental and modelling studies should quantify the roles of drop height and microtopography magnitude (involving various stalagmite morphologies) on vertical growth. Future possibilities include constraining past variability in multiple environmental parameters from stalagmite data; such an approach is 
tenable because only a limited proportion of parameter space will produce good model fits to data (e.g., Sr concentrations), and there are now studies confirming the sufficiency of existing growth rate theory on various time scales. Finally, for well-monitored cave systems, modelling growth provides a way to quantify biases in geochemical proxy data, aiding the interpretation of records irrespective of resolution.

\section{Acknowledgements}

This research was funded by a Sir Kingsley Dunham Studentship awarded to AJB. We gratefully acknowledge C. Wintrip, Chief Mechanical Technician in Durham's School of Engineering and Computing Sciences, for machining the experimental apparatus and D. Wheeler, University of Sunderland, for kindly providing meteorological data. E. Llewellin, T. Watton and I. Walczak are thanked for helpful discussion. We are grateful to C. Day and two anonymous reviewers, whose comments much improved the first draft of this paper, and G. Henderson for his editorial assistance.

\section{Author contributions}

AJB and JULB designed the experimental set-up for dripwater film measurements. AJB undertook the measurements and devised the time series model. DPM conducted cave monitoring, sampled Gib04a, and conducted trace element analyses. AJB analysed the modelling results and wrote the paper. All authors approved the final manuscript draft.

\section{References}

Baker, A. and Bradley, C., 2010. Modern stalagmite $\delta^{18} \mathrm{O}$ : Instrumental calibration and forward modelling. Glob. Planet. Change 71, 201-206.

Baker, A., Genty, D., Dreybrodt, W., Barnes, W. L., Mockler, N. J., and Grapes, J., 1998. Testing theoretically predicted stalagmite growth rate with Recent annually laminated samples: Implications for past stalagmite deposition. Geochim. Cosmochim. Acta 62, 393-404.

Baker, A. and Smart, P. L., 1995. Recent flowstone growth rates: Field measurements in comparison to theoretical predictions. Chem. Geol. 122, 121-128.

Baker, A., Smith, C. L., Jex, C., Fairchild, I. J., Genty, D., and Fuller, L., 2008. Annually Laminated Speleothems: a Review. Int. J. Speleol. 37, 193-206.

Baldini, J. U. L., McDermott, F., Baker, A., Baldini, L. M., Mattey, D. P., and Railsback, L. B., 2005. Biomass effects on stalagmite growth and isotope ratios: A 20th century analogue from Wiltshire, England. Earth Planet. Sci. Lett. 240, 486-494.

Baldini, J. U. L., McDermott, F., and Fairchild, I. J., 2006. Spatial variability in cave drip water hydrochemistry: Implications for stalagmite paleoclimate records. Chem. Geol. 235, 390-404.

Baldini, J. U. L., McDermott, F., Hoffmann, D. L., Richards, D. A., and Clipson, N., 2008. Very high-frequency and seasonal cave atmosphere $\mathrm{P}_{\mathrm{CO} 2}$ variability: Implications for 
stalagmite growth and oxygen isotope-based paleoclimate records. Earth Planet. Sci. Lett. 272, 118-129.

Banner, J. L., Guilfoyle, A., James, E. W., Stern, L. A., and Musgrove, M., 2007. Seasonal variations in modern speleothem calcite growth in Central Texas, USA. J. Sed. Res. 77, 615-622.

Boch, R., 2008. Stalagmites from Katerloch Cave, Austria: Growth dynamics and highresolution records of climate change. $\mathrm{PhD}$ thesis, Leopold-Franzens-Universität Innsbruck.

Borsato, A., Frisia, S., Fairchild, I. J., Somogyi, A., and Susini, J., 2007. Trace element distribution in annual stalagmite laminae mapped by micrometer-resolution X-ray fluorescence: Implications for incorporation of environmentally significant species. Geochim. Cosmochim. Acta 71, 1494-1512.

Bradley, C., Baker, A., Jex, C. N., and Leng, M. J., 2010. Hydrological uncertainties in the modelling of cave drip-water $\delta^{18} \mathrm{O}$ and the implications for stalagmite palaeoclimate reconstructions. Quat. Sci. Rev. 29, 2201-2214.

Buhmann, D. and Dreybrodt, W., 1985. The Kinetics of Calcite Dissolution and Precipitation in Geologically Relevant Situations of Karst Areas 1. Open System. Chem. Geol. 48, 189-211.

Collister, C. and Mattey, D., 2008. Controls on water drop volume at speleothem drip sites: An experimental study. J. Hydrol. 358, 259-267.

Darling, W. G., 2004. Hydrological factors in the interpretation of stable isotopic proxy data present and past: a European perspective. Quat. Sci. Rev. 23, 743-770.

Day, C. C. and Henderson, G. M., 2013. Controls on trace-element partitioning in caveanalogue calcite. Geochim. Cosmochim. Acta 120, 612-627.

Dreybrodt, W., 1980. Deposition of calcite from thin films of natural calcareous solutions and the growth of speleothems. Chem. Geol. 29, 89-105.

Dreybrodt, W., 1981. The kinetics of calcite precipitation from thin films of calcareous solutions and the growth of speleothems: revisited. Chem. Geol. 32, 237-245.

Dreybrodt, W., 1988. Processes in Karst Systems: Physics, Chemistry, and Geology. Springer Series in Physical Environment. 4. Springer-Verlag, Berlin. 288 pp.

Dreybrodt, W., 1999. Chemical kinetics, speleothem growth and climate. Boreas 28, 347356.

Fairchild, I. J. and Baker, A., 2012. Speleothem Science: From Process to Past Environments. Blackwell Quaternary Geoscience Series. Wiley-Blackwell, Chichester. 432 pp.

Fairchild, I. J., Baker, A., Borsato, A., Frisia, S., Hinton, R. W., McDermott, F., and Tooth, A. F., 2001. Annual to sub-annual resolution of multiple trace-element trends in speleothems. J. Geol. Soc. 158, 831-841.

Fairchild, I. J., Smith, C. L., Baker, A., Fuller, L., Spötl, C., Mattey, D., McDermott, F., and E.I.M.F., 2006. Modification and preservation of environmental signals in speleothems. Earth-Sci. Rev. 75, 105-153.

Fairchild, I. J. and Treble, P. C., 2009. Trace elements in speleothems as recorders of environmental change. Quat. Sci. Rev. 28, 449-468.

Frisia, S., Borsato, A., Fairchild, I. J., and McDermott, F., 2000. Calcite fabrics, growth mechanisms, and environments of formation in speleothems from the Italian Alps and southwestern Ireland. J. Sed. Res. 70, 1183-1196.

Gabitov, R. I., Sadekov, A., and Leinweber, A., 2014. Crystal growth rate effect on $\mathrm{Mg} / \mathrm{Ca}$ and $\mathrm{Sr} / \mathrm{Ca}$ partitioning between calcite and fluid: An in situ approach. Chem. Geol. 367, 70-82.

Gabitov, R. I. and Watson, E. B., 2006. Partitioning of strontium between calcite and fluid. Geochem. Geophys. Geosys. 7, Q11004. 
Genty, D., Baker, A., and Vokal, B., 2001. Intra- and inter-annual growth rate of modern stalagmites. Chem. Geol. 176, 191-212.

Genty, D. and Quinif, Y., 1996. Annually laminated sequences in the internal structure of some Belgian stalagmites - Importance for paleoclimatology. J. Sed. Res. 66, 275288.

Hansen, M., Dreybrodt, W., and Scholz, D., 2013. Chemical evolution of dissolved inorganic carbon species flowing in thin water films and its implications for (rapid) degassing of $\mathrm{CO}_{2}$ during speleothem growth. Geochim. Cosmochim. Acta 107, 242-251.

Huang, H. M., Fairchild, I. J., Borsato, A., Frisia, S., Cassidy, N. J., McDermott, F., and Hawkesworth, C. J., 2001. Seasonal variations in $\mathrm{Sr}, \mathrm{Mg}$ and $\mathrm{P}$ in modern speleothems (Grotta di Ernesto, Italy). Chem. Geol. 175, 429-448.

Huang, Y. M. and Fairchild, I. J., 2001. Partitioning of $\mathrm{Sr}^{2+}$ and $\mathrm{Mg}^{2+}$ into calcite under karstanalogue experimental conditions. Geochim. Cosmochim. Acta 65, 47-62.

IAEA/WMO, 2014. Global Network of Isotopes in Precipitation. The GNIP Database.

Johnson, K. R., Hu, C. Y., Belshaw, N. S., and Henderson, G. M., 2006. Seasonal traceelement and stable-isotope variations in a Chinese speleothem: The potential for highresolution paleomonsoon reconstruction. Earth Planet. Sci. Lett. 244, 394-407.

Kaufmann, G., 2003. Stalagmite growth and palaeo-climate: the numerical perspective. Earth Planet. Sci. Lett. 214, 251-266.

Kaufmann, G. and Dreybrodt, W., 2004. Stalagmite growth and palaeo-climate: an inverse approach. Earth Planet. Sci. Lett. 224, 529-545.

Lorens, R. B., 1981. Sr, Cd, Mn and Co distribution coefficients in calcite as a function of calcite precipitation rate. Geochim Cosmochim Ac 45, 553-561.

Mattey, D. P., Fairchild, I. J., Atkinson, T. C., Latin, J.-P., Ainsworth, M., and Durell, R., 2010. Seasonal microclimate control of calcite fabrics, stable isotopes and trace elements in modern speleothem from St Michaels Cave, Gibraltar, in: Pedley, H. M. and Rogerson, M. (Ed.) Tufas and Speleothems: Unravelling the Microbial and Physical Controls. Geological Society of London Special Publication 336. pp. 323344.

Mattey, D. P., Lowry, D., Duffet, J., Fisher, R., Hodge, E., and Frisia, S., 2008. A 53 year seasonally resolved oxygen and carbon isotope record from a modern Gibraltar speleothem: Reconstructed drip water and relationship to local precipitation. Earth Planet. Sci. Lett. 269, 80-95.

McGarry, S. F. and Baker, A., 2000. Organic acid fluorescence: applications to speleothem palaeoenvironmental reconstruction. Quat. Sci. Rev. 19, 1087-1101.

Murthy, R., Griffin, K. L., Zarnoch, S. J., Dougherty, P. M., Watson, B., Van Haren, J., Patterson, R. L., and Mahato, T., 2003. Carbon dioxide efflux from a $550 \mathrm{~m}^{3}$ soil across a range of soil temperatures. Forest Ecol. Man. 178, 311-327.

Patra, K. C., 2001. Hydrology and Water Resources Engineering. CRC Press, Boca Raton, Florida. $561 \mathrm{pp}$.

Polyak, V. J. and Asmerom, Y., 2001. Late Holocene climate and cultural changes in the southwestern United States. Science 294, 148-151.

Proctor, C. J., Baker, A., Barnes, W. L., and Gilmour, R. A., 2000. A thousand year speleothem proxy record of North Atlantic climate from Scotland. Clim. Dyn. 16, 815-820.

Rodríguez-Vidal, J., Cáceres, L. M., Finlayson, J. C., Gracia, F. J., and Martínez-Aguirre, A., 2004. Neotectonics and shoreline history of the Rock of Gibraltar, southern Iberia. Quat. Sci. Rev. 23, 2017-2029.

Schneider, C. A., Rasband, W. S., and Eliceiri, K. W., 2012. NIH Image to ImageJ: 25 years of image analysis. Nat. Methods 9, 671-675. 
Sherwin, C. M. and Baldini, J. U. L., 2011. Cave air and hydrological controls on prior calcite precipitation and stalagmite growth rates: Implications for palaeoclimate reconstructions using speleothems. Geochim. Cosmochim. Acta 75, 3915-3929.

Spötl, C., Fairchild, I. J., and Tooth, A. F., 2005. Cave air control on dripwater geochemistry, Obir Caves (Austria): Implications for speleothem deposition in dynamically ventilated caves. Geochim. Cosmochim. Acta 69, 2451-2468.

Thornthwaite, C. W., 1948. An approach toward a rational classification of climate. Geogr. Rev. 38, 55-94.

Tratman, E. K., 1971. The formation of the Gibraltar Caves. Trans. Cave Res. Group G.B. 13, 135-143.

Wheeler, D. A., 2006. The Gibraltar climate record: Part 1 - the history of weather observations. Weather 61, 36-39.

Wheeler, D. A., 2007. The Gibraltar climate record: Part 2 - precipitation. Weather 62, 99104.

Wheeler, D. A., 2011. The Gibraltar climatic record - Part 3. Temperature. Weather 66, 259265.

Whitaker, T., Jones, D., Baldini, J. U. L., and Baker, A. J., 2009. A high-resolution spatial survey of cave air carbon dioxide concentrations in Scoska Cave (North Yorkshire, UK): implications for calcite deposition and re-dissolution. Cave Karst Sci. 36, 85-92.

Wong, C. I., Banner, J. L., and Musgrove, M., 2011. Seasonal dripwater $\mathrm{Mg} / \mathrm{Ca}$ and $\mathrm{Sr} / \mathrm{Ca}$ variations driven by cave ventilation: Implications for and modeling of speleothem paleoclimate records. Geochim. Cosmochim. Acta 75, 3514-3529. 


\begin{tabular}{ccccc} 
Surface & $\boldsymbol{\rho}(\mathbf{m m})$ & $\boldsymbol{\rho}^{-\mathbf{1}}\left(\mathbf{m m}^{\mathbf{- 1}}\right)$ & Height $(\mathbf{m m})$ & Mean $\boldsymbol{\delta}(\mathbf{m m})$ \\
\hline 11 & 36.5 & 0.027 & 45.59 & 0.232 \\
10 & 29.0 & 0.034 & 42.35 & 0.129 \\
9 & 40.0 & 0.025 & 36.03 & 0.267 \\
8 & 58.0 & 0.017 & 29.56 & 0.379 \\
7 & 77.0 & 0.013 & 25.15 & 0.440 \\
6 & 72.0 & 0.014 & 19.85 & 0.427 \\
5 & 88.0 & 0.011 & 17.21 & 0.464 \\
4 & 155.0 & 0.006 & 12.21 & 0.535 \\
3 & 25.5 & 0.039 & 8.09 & $0.061^{\mathrm{b}}$ \\
2 & 39.0 & 0.026 & 7.06 & $0.257^{\mathrm{b}}$ \\
1 & 157.0 & 0.006 & 0.00 & $0.536^{\mathrm{a}}$ \\
\hline & & & & $0.365^{\mathrm{c}}$
\end{tabular}

Table 1. Film thickness for Gib04a growth laminae based on experimental measurements. Estimated curvature and associated mean film thickness (given as the mean of values calculated using both transfer functions in Fig. 4) for 11 growth surfaces identified in Gib04a (Fig. 5). For each surface, height denotes the start point of the interval of vertical calcite accumulation for the estimated $\delta$ is used in the growth model.

${ }^{a}$ Initial surface from which modern growth initiated.

${ }^{\mathrm{b}}$ Non-uniform stalagmite growth (see text for discussion).

${ }^{\mathrm{c}}$ Growth-weighted mean value. 


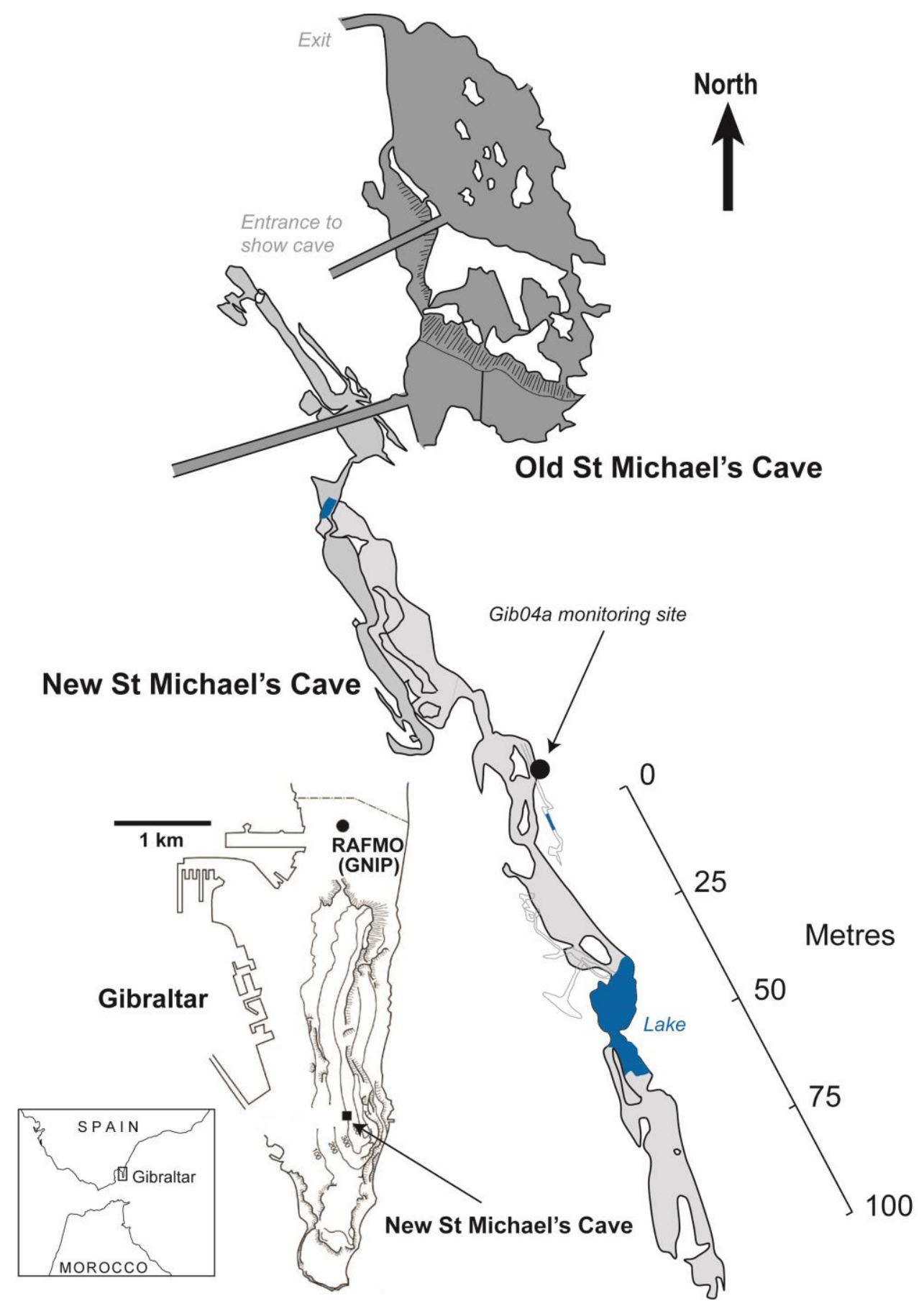

Figure 1. Location and most recent survey map (undertaken in 2007) of NSM Cave and location and map of Gibraltar with locations of Gibraltar's RAFMO/GNIP station at North Front (World Meteorological Organisation station code: $8495 ; 36.2^{\circ} \mathrm{N}, 5.4{ }^{\circ} \mathrm{W}, 5 \mathrm{~m}$ asl). Topographic contour lines on the Gibraltar map are in 100 metre intervals. Figure adapted from Mattey et al. (2010). 

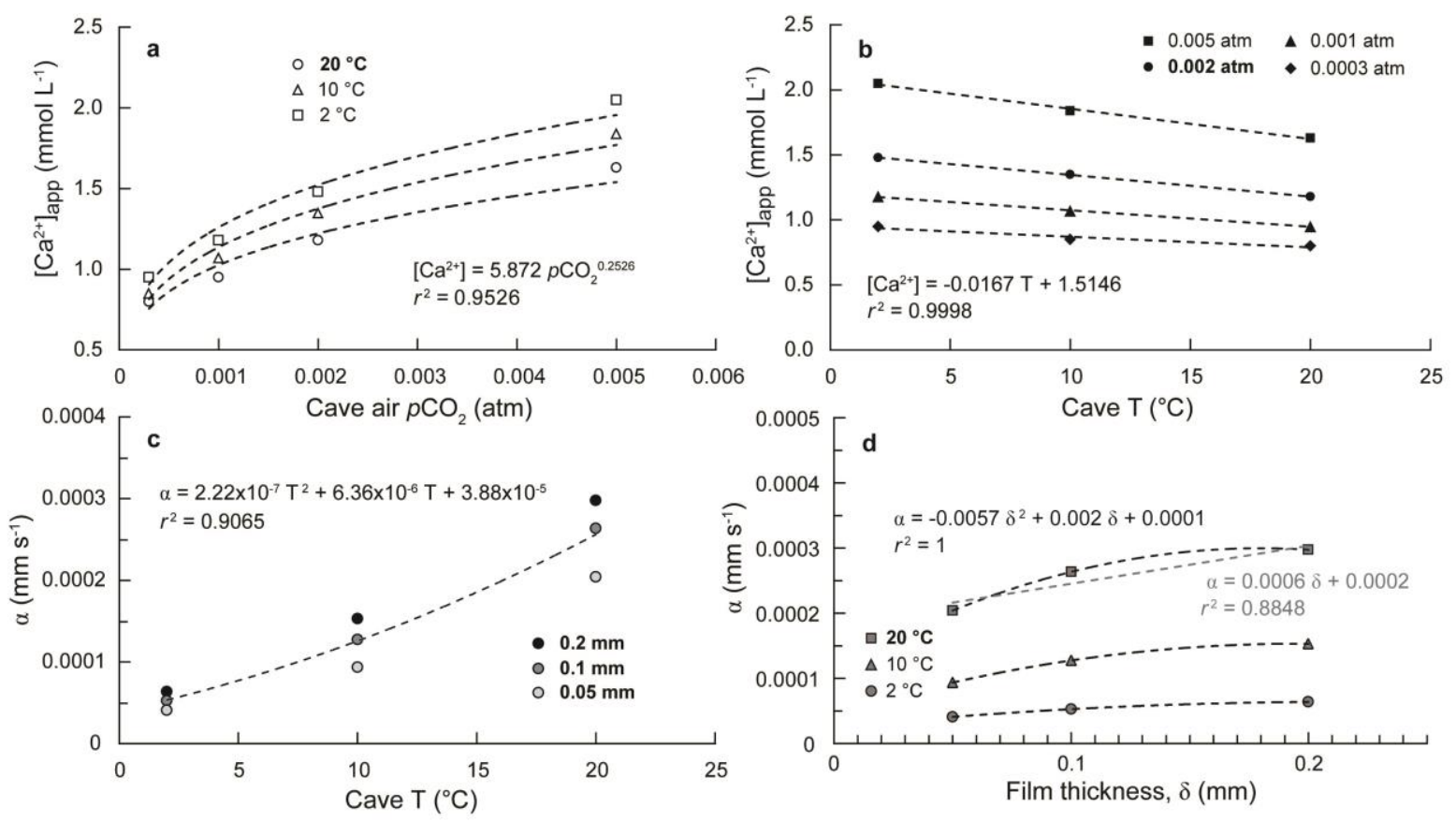

Figure 2. A synthesis of data originally presented by Dreybrodt (1999) and transfer functions derived from these data by bivariate regression, which are used in the time series growth reconstruction for Gib04a. (a) A power law fit (correlation coefficient, $r^{2}=0.95$ ) between $\left[\mathrm{Ca}^{2+}\right]_{\text {app }}$ and cave atmosphere $p \mathrm{CO}_{2}$ for a constant cave temperature of $20{ }^{\circ} \mathrm{C}$. (b) A linear fit $\left(r^{2}=0.99\right)$ between $\left[\mathrm{Ca}^{2+}\right]_{a p p}$ and temperature for a constant $p \mathrm{CO}_{2}$ of $0.002 \mathrm{~atm}$. (c) A $2^{\text {nd }}-$ order polynomial fit $\left(r^{2}=0.91\right)$ between the 'kinetic constant' $(\alpha)$ and cave temperature for all data. (d) A $2^{\text {nd }}$-order polynomial fit $\left(r^{2}=1\right)$ between $\alpha$ and film thickness $(\delta)$ for a constant temperature of $20^{\circ} \mathrm{C}$. A linear fit $\left(r^{2}=0.89\right)$ is also shown for comparison, but not used in the growth reconstruction (grey line). Terms are defined in the text. 


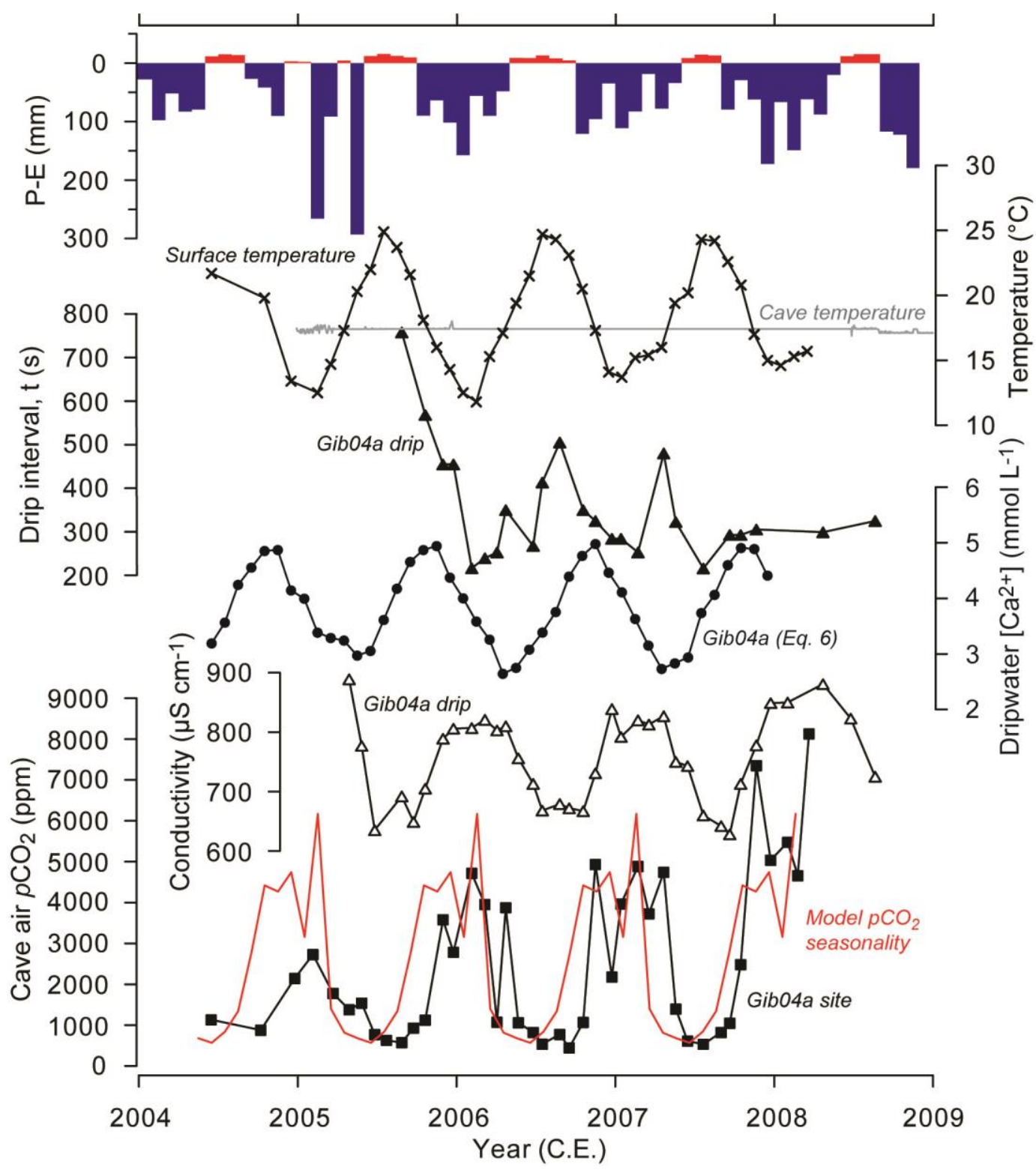

Figure 3. Monitoring data (2004-2009) from the Gib04a drip site in NSM Cave (Fig. 1) and calculated model parameters: cave atmosphere $p \mathrm{CO}_{2}$ spot measurements (squares) and monthly mean trend (red line); dripwater electrical conductivity (triangles); modelled dripwater $\left[\mathrm{Ca}^{2+}\right]$ using Eq. 6 (circles); drip discharge (filled triangles); surface temperature measured at Gibraltar's RAFMO station (crosses) and continuously logged cave air temperature (grey line); surface water excess (blue - positive, red - negative) calculated by subtracting potential evapotranspiration (E) from total monthly rainfall (GNIP data). We calculated E according to the method of Thornthwaite (1948), following Mattey et al. (2008), with heat index values and reduction factors taken from Patra (2001). Cave monitoring data were originally published by Mattey et al. $(2010 ; 2008)$. RAFMO meteorological data $(0$ Crown Copyright, the Met Office. 

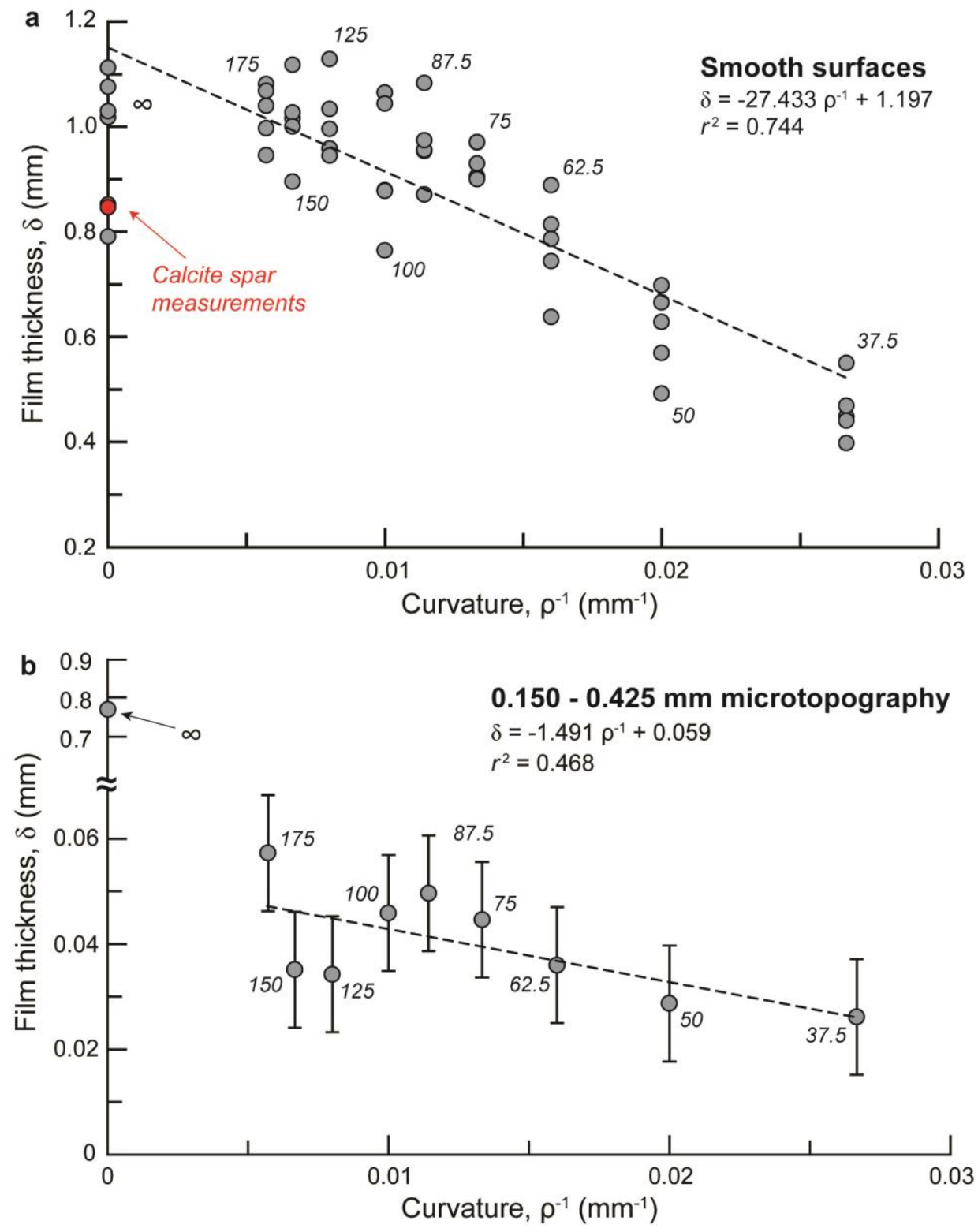

Figure 4. Change in film thickness $(\delta)$ as a function of surface curvature $(\rho)$ for wetted surfaces; $\delta$ increases with decreasing curvature. (a) Smooth surfaces $\left(r^{2}=0.74 ; p=8.48 \times 10^{-}\right.$ $\left.{ }^{16} ; n=50\right)$ and (b) surfaces with $0.15-0.425 \mathrm{~mm}$ microtopography $\left(r^{2}=0.47 ; p=0.09 ; n=\right.$ 9). Mean values for wetted calcite $\operatorname{spar}$ (red; $n=7 ; \sigma=0.012$ ) are shown in (a). The $\delta$ values determined for smooth surfaces are an order of magnitude greater than those for microtopographical surfaces. In the case of flat (infinite curvature) surfaces, $\delta$ values are similar, indicating that wet $\mathrm{Al}$ provides a useful, though not perfect, analogue for calcite, supporting recent research (e.g., Collister and Mattey, 2008). 


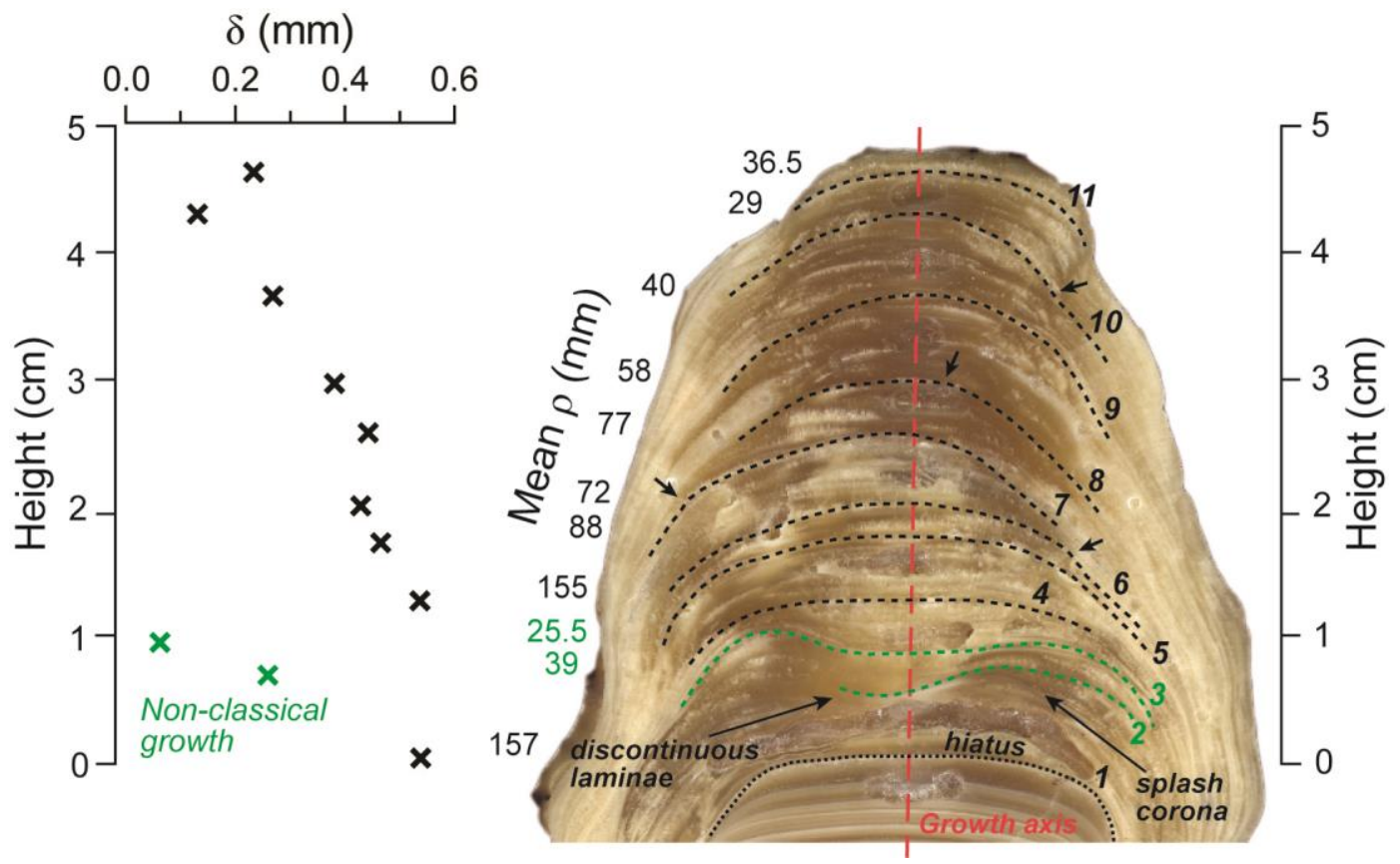

Figure 5. Cut section of the modern growth of Gib04a (AD 1951-2004). The dotted line indicates the hiatus separating ancient (pre-Holocene) and modern growth, termed growth surface 1 . The dashed lines indicate laminae 2 to 11 . For each lamina, estimated curvature $(\mathrm{mm})$ is given on the left, with corresponding mean $\delta$ values plotted against height (see also Table 1). Laminae 2 and 3 (highlighted green) represent non-uniform stalagmite growth. The dashed red line indicates the vertical growth axis and the black arrows indicate clear inflections in laminae curvature that are visible in this 2-D cut section. See text for discussion. 



Figure 6. The full $R_{0}$ reconstruction (black), with a magnification of the period January 1987 to April 2004 that is compared with Gib04a Sr concentration (blue). Sr data originally published by Mattey et al. (2008). 


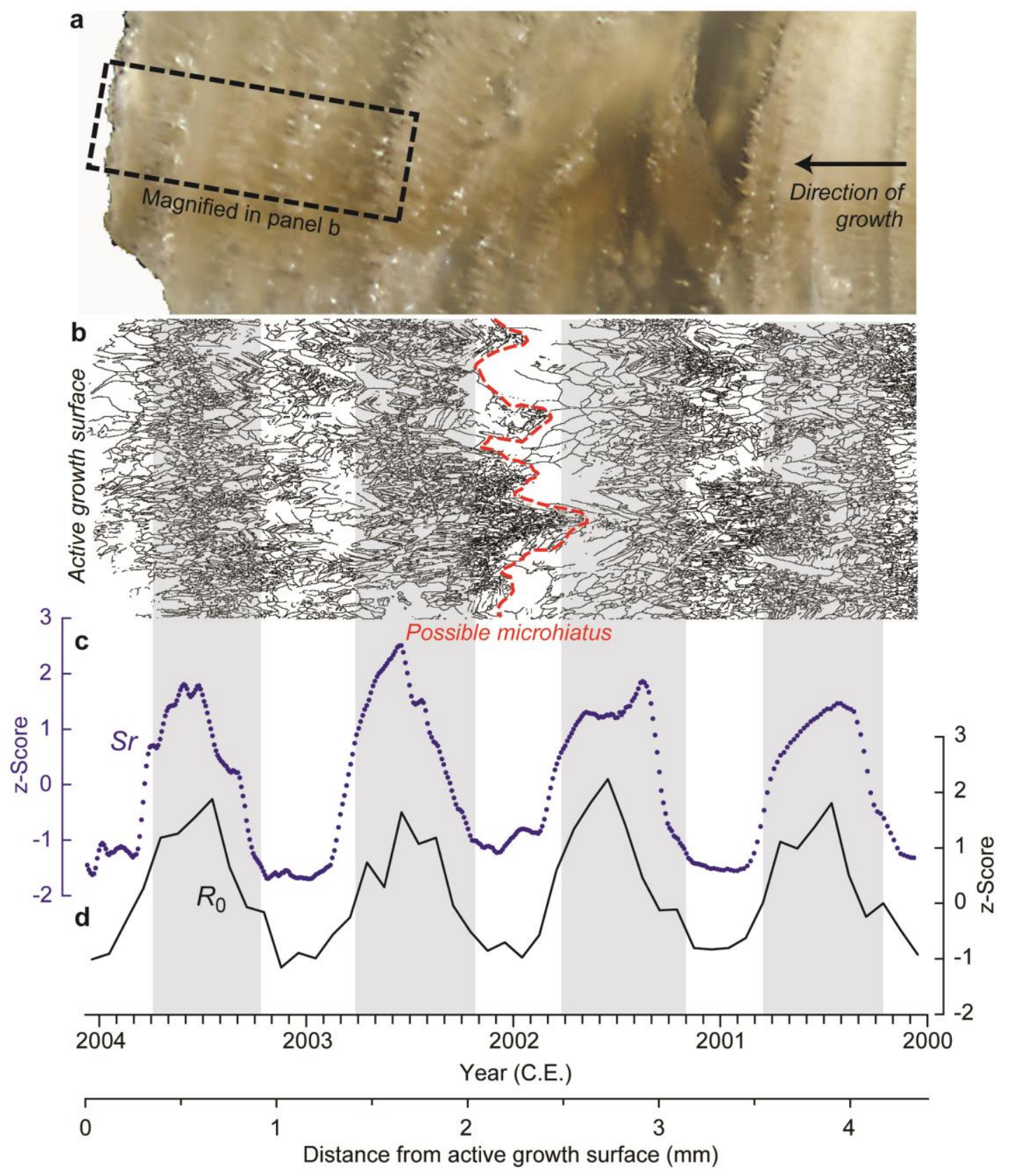

Figure 7. Comparison of modelled growth during the period 2000 to April 2004 (corresponding to the upper $\sim 4 \mathrm{~mm}$ of Gib04a) with (a) Gib04a petrography, (b) an electron backscatter grain boundary map of the area outlined in (a), and (c) high-resolution $\mathrm{Sr}$ concentration transect across the upper $\sim 4 \mathrm{~mm}$ of Gib04a (blue), each of which were originally published by Mattey et al. (2010). (d) Reconstructed growth seasonality over this period, totalling $4.18 \mathrm{~mm}$ (black). Both $\mathrm{Sr}$ and $R_{0}$ are plotted as normalised z-Scores, calculated by subtracting the mean and dividing by 1 standard deviation, so that the amplitude of seasonal changes in each dataset may be compared fairly. Vertical grey shading illustrates the association of $R_{0}, \mathrm{Sr}$, and grain-scale calcite fabric. See text for discussion. 


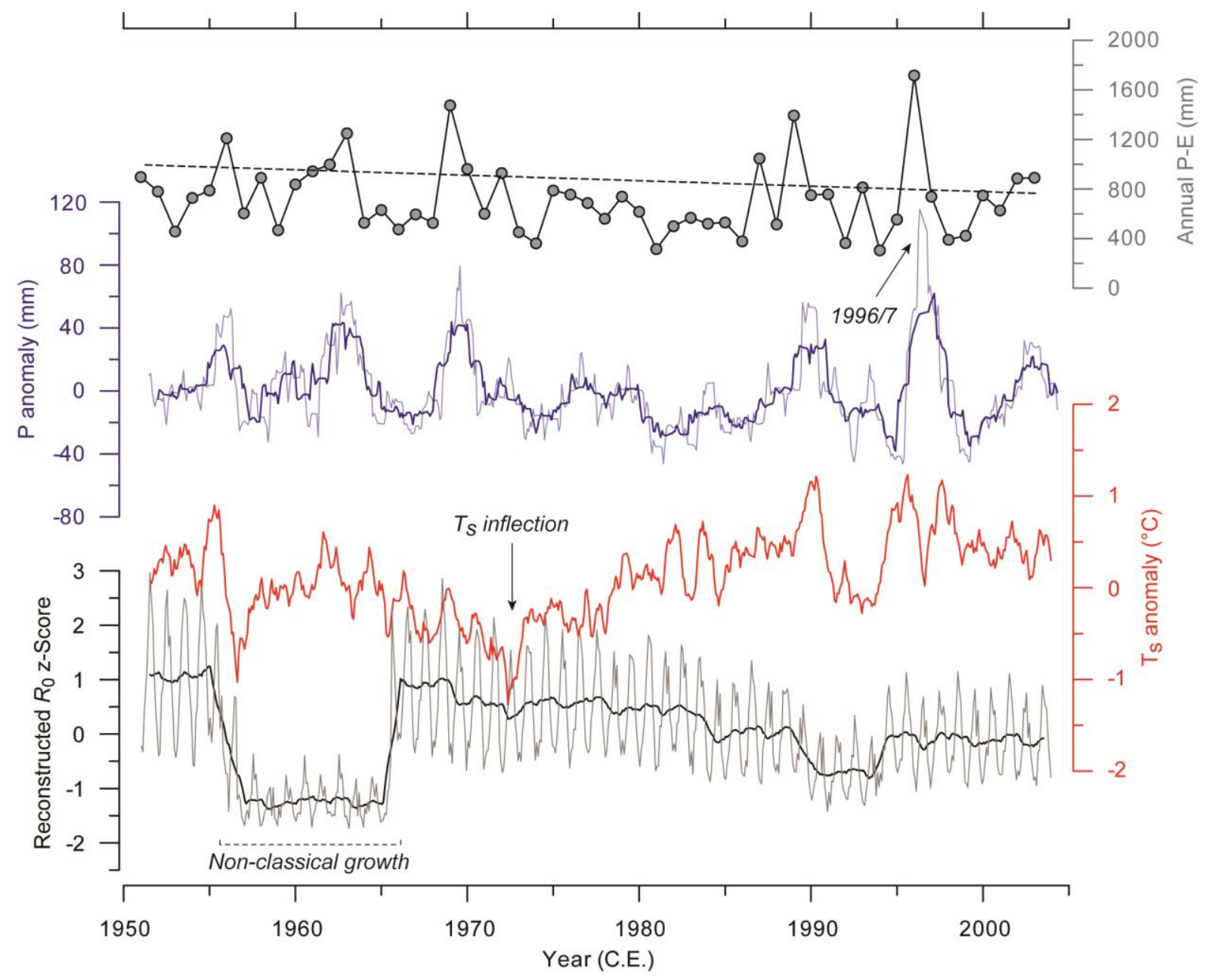

Figure 8. Comparison of $R_{0}$ (grey; black curve is a 12-month running mean) with $\mathrm{T}_{\mathrm{s}}$ anomalies (red), $\mathrm{P}$ anomalies (pale blue; dark blue curve is a 24-month running mean), and total annual water excess during the period 1951-2004 (grey). The non-uniform period of Gib04a growth (Fig. 6), an inflection in secular $\mathrm{T}_{\mathrm{s}}$ variability, and the anomalously wet 1996/1997 winter are indicated. 


\section{Supplementary Material}

\section{Reconstructing modern stalagmite growth from cave monitoring, local meteorology, and experimental measurements of dripwater films}

Alexander J. Baker ${ }^{1, *}$, David P. Mattey ${ }^{2}$, and James U. L. Baldini ${ }^{1}$

${ }^{1}$ Department of Earth Sciences, University of Durham, Science Laboratories, South Road, Durham, DH1 3LE, U.K.

${ }^{2}$ Department of Earth Sciences, Royal Holloway, University of London, Egham, TW20 0EX, U.K. *a.j.baker@durham.ac.uk

\section{S1. Experimental setup for $\delta$ measurements}

The experimental setup (Fig. S1) uses a fixed camera viewshed in order to obtain consistent images of water droplets. An example photograph (Fig. S2) shows a drip at rest on the surface of a curved wetted Al surface. An $80 \mu \mathrm{l}$ droplet spreads over a dome apex for between $\sim 0.5$ and $\sim 3$ seconds under wetted conditions. Therefore, the time allowed for each droplet to spread is different depending on dome curvature because the more curved the dome, the longer the spreading time. However, each droplet was able to come to rest on the domes we used, which are $50-90 \mathrm{~mm}$ in diameter, without loss of water.

The addition of dye slightly alters the flow properties of the water used in our experimental measurements. However, it is difficult to provide a quantitative assessment of this because image analysis is less precise when using non-dyed water. Determining the boundary of a water film using image analysis (Fig. S2) is very precise when a detectable colour contrast exists. However, our measurements are in close agreement with those of Baker et al. (1998), obtained with a Vernier spherometer and without dye, suggesting that the effect of dying on water flow is minimal.

Photographs were processed (colour thresholding, binary conversion, scaling and particle analysis) using ImageJ (Schneider et al., 2012). Image analysis provide a precise measurement of the projected area covered by the dispensed water droplet and ultimately of mean film thickness because droplet volume and surface curvature are known (Eq. 3). Our $\delta$ calculations are provided in Table $\mathrm{S} 1$.

\section{S2. Sr partitioning and additional validation of Gib04a growth reconstruction}

To further test the validity of the $R_{0}$ reconstruction, how well its output captures the partitioning of $\mathrm{Sr}$ between calcite and dripwater solution is examined. Unfortunately, the available dripwater hydrochemistry and Gib04a trace element time series datasets do not overlap, which is compensated for by calculating $\mathrm{K}_{\mathrm{d}}^{\mathrm{Sr}}$ based on modelled $R_{0}$. We extended the 
$R_{0}$ reconstruction beyond the sampling date of Gib04a, through the cave monitoring period, and derived $\mathrm{K}_{\mathrm{d}}^{\mathrm{Sr}}$ variability from these hypothetical vertical growth rate values using the relationship of Gabitov and Watson (2006). (Our aim is not to provide modelling constraints on $\mathrm{K}_{\mathrm{d}}^{\mathrm{Sr}}$ in speleothem calcite that may be used directly in future studies; we aim only to undertake an assessment of the $R_{0}$-Sr comparison for Gib04a.) Mean calculated $\mathrm{K}_{\mathrm{d}}^{\mathrm{Sr}}$ between 2005 and 2007 is 0.39 (Fig. S3), which is higher than but close to experimentally-determined values (Day and Henderson, 2013; Gabitov et al., 2014; Gabitov and Watson, 2006; Huang and Fairchild, 2001; Lorens, 1981; Tang et al., 2008; Tesoriero and Pankow, 1996) and natural speleothem calcite values deposited at cave temperatures comparable to those of NSM Cave (Bourdin et al., 2011; Gascoyne, 1983). This overestimation is expected, given the higher vertical extension rate of Gib04a relative to the rates considered in those studies. This comparison is made cautiously because higher $\mathrm{K}_{d}^{\mathrm{Sr}}$ values in some experimental studies were derived at instantaneous growth rates which are higher than those applicable to speleothem deposition (Day and Henderson, 2013). Nevertheless, this result is broadly consistent with association between vertical calcite growth, calcite fabrics, and $\mathrm{Sr}$ concentration variability identified in Gib04a (Fig. 7), but other factors (e.g., karst hydrology, crystallographic growth kinetics) influence Sr incorporation into speleothem calcite (Fairchild and Baker, 2012).

\section{S3. Sensitivity of vertical extension rate to $\delta$}

The full $R_{0}$ reconstruction, including surface environmental variables and dripwater $\left[\mathrm{Ca}^{2+}\right]$, calculated using Eq. 6, are provided in Table S2. Quantifications of the sensitivity of $R_{0}$ to various parameters are largely absent from the literature. We conducted a first-order assessment of the $\delta$-sensitivity of $R_{0}$ by re-calculating Gib04a $R_{0}$ during the period 1951-2004 using constant values of $\delta$ and $\alpha$ and comparing this to the original Gib04a growth reconstruction. Theoretically, assessing $R_{0}$ 's sensitivity to $\delta$ alone is not possible because $\alpha$ partially depends on $\delta$ (Eq. 5 and Fig. 2c, d). Therefore, this sensitivity test takes $\alpha$ into account, but because $\mathrm{T}_{\mathrm{c}}$ is approximately constant (Fig. 3), primarily reflects $\delta$. Gib04a $R_{0}$ was recalculated using a weighted mean values of $\delta(0.365 \mathrm{~mm}$; Table 1$)$ and $\alpha\left(5.12 \times 10^{-4}\right.$ $\mathrm{mm} \mathrm{s}^{-1}$ ). All other growth conditions remained as per the original $R_{0}$ reconstruction (Fig. 6). Recalculated in this way, the total vertical Gib04a growth during 1951-2004 is $6.3 \mathrm{~mm}$, which underestimates actual vertical growth by an order of magnitude. The recalculated data are poorly, negatively correlated with the original reconstruction $\left(r^{2}=0.23\right)$ and exhibit much scatter. Many recalculated $R_{0}$ values are negative (Fig. S4), which suggest potential redissolution of previously-deposited calcite (Baldini et al., 2006a; Whitaker et al., 2009), causing microhiatuses in growth, but the original $R_{0}$ reconstruction and $\mathrm{Sr}$ data indicate that this is not the case. Moreover, the largest $R_{0}$ values in the original monthly reconstruction, though potential overestimates, in fact correspond to negative values in the recalculation with constant $\delta$. The seasonal timing of these negative values therefore indicates they are implausible. Overall, this strongly suggests that using a single value for $\delta$ is not appropriate for modelling $R_{0}$ on interannual timescales and classical stalagmite growth can be 
significantly sensitive to $\delta$, with important implications for quantifying the cave and meteorological controls on Gib04a morphology and vertical growth.

\section{Supplementary references}

Baker, A., Genty, D., Dreybrodt, W., Barnes, W. L., Mockler, N. J., and Grapes, J., 1998. Testing theoretically predicted stalagmite growth rate with Recent annually laminated samples: Implications for past stalagmite deposition. Geochim. Cosmochim. Acta 62, 393-404.

Baldini, J. U. L., Baldini, L. M., McDermott, F., and Clipson, N., 2006. Carbon dioxide sources, sinks, and spatial variability in shallow temperate zone caves: Evidence from Ballynamintra Cave, Ireland. J. Cave Karst Stud. 68, 4-11.

Bourdin, C., Douville, E., and Genty, D., 2011. Alkaline-earth metal and rare-earth element incorporation control by ionic radius and growth rate on a stalagmite from the Chauvet Cave, Southeastern France. Chem. Geol. 290, 1-11.

Day, C. C. and Henderson, G. M., 2013. Controls on trace-element partitioning in caveanalogue calcite. Geochim. Cosmochim. Acta 120, 612-627.

Fairchild, I. J. and Baker, A., 2012. Speleothem Science: From Process to Past Environments. Blackwell Quaternary Geoscience Series. Wiley-Blackwell, Chichester. 432 pp.

Gabitov, R. I., Sadekov, A., and Leinweber, A., 2014. Crystal growth rate effect on $\mathrm{Mg} / \mathrm{Ca}$ and $\mathrm{Sr} / \mathrm{Ca}$ partitioning between calcite and fluid: An in situ approach. Chem. Geol. In press.

Gabitov, R. I. and Watson, E. B., 2006. Partitioning of strontium between calcite and fluid. Geochem. Geophys. Geosys. 7, Q11004.

Gascoyne, M., 1983. Trace-element partition coefficients in the calcite-water system and their paleoclimatic significance in cave studies. J. Hydrol. 61, 213-222.

Huang, Y. M. and Fairchild, I. J., 2001. Partitioning of $\mathrm{Sr}^{2+}$ and $\mathrm{Mg}^{2+}$ into calcite under karstanalogue experimental conditions. Geochim. Cosmochim. Acta 65, 47-62.

Lorens, R. B., 1981. Sr, Cd, Mn and Co distribution coefficients in calcite as a function of calcite precipitation rate. Geochim Cosmochim Ac 45, 553-561.

Schneider, C. A., Rasband, W. S., and Eliceiri, K. W., 2012. NIH Image to ImageJ: 25 years of image analysis. Nat. Methods 9, 671-675.

Tang, J., Köhler, S. J., and Dietzel, M., 2008. $\mathrm{Sr}^{2+} / \mathrm{Ca}^{2+}$ and ${ }^{44} \mathrm{Ca} /{ }^{40} \mathrm{Ca}$ fractionation during inorganic calcite formation: I. Sr incorporation. Geochim. Cosmochim. Acta 72, 3718-3732.

Tesoriero, A. J. and Pankow, J. F., 1996. Solid solution partitioning of $\mathrm{Sr}^{2+}, \mathrm{Ba}^{2+}$, and $\mathrm{Cd}^{2+}$ to calcite. Geochim. Cosmochim. Acta 60, 1053-1063.

Whitaker, T., Jones, D., Baldini, J. U. L., and Baker, A. J., 2009. A high-resolution spatial survey of cave air carbon dioxide concentrations in Scoska Cave (North Yorkshire, UK): implications for calcite deposition and re-dissolution. Cave Karst Sci. 36, 85-92. 


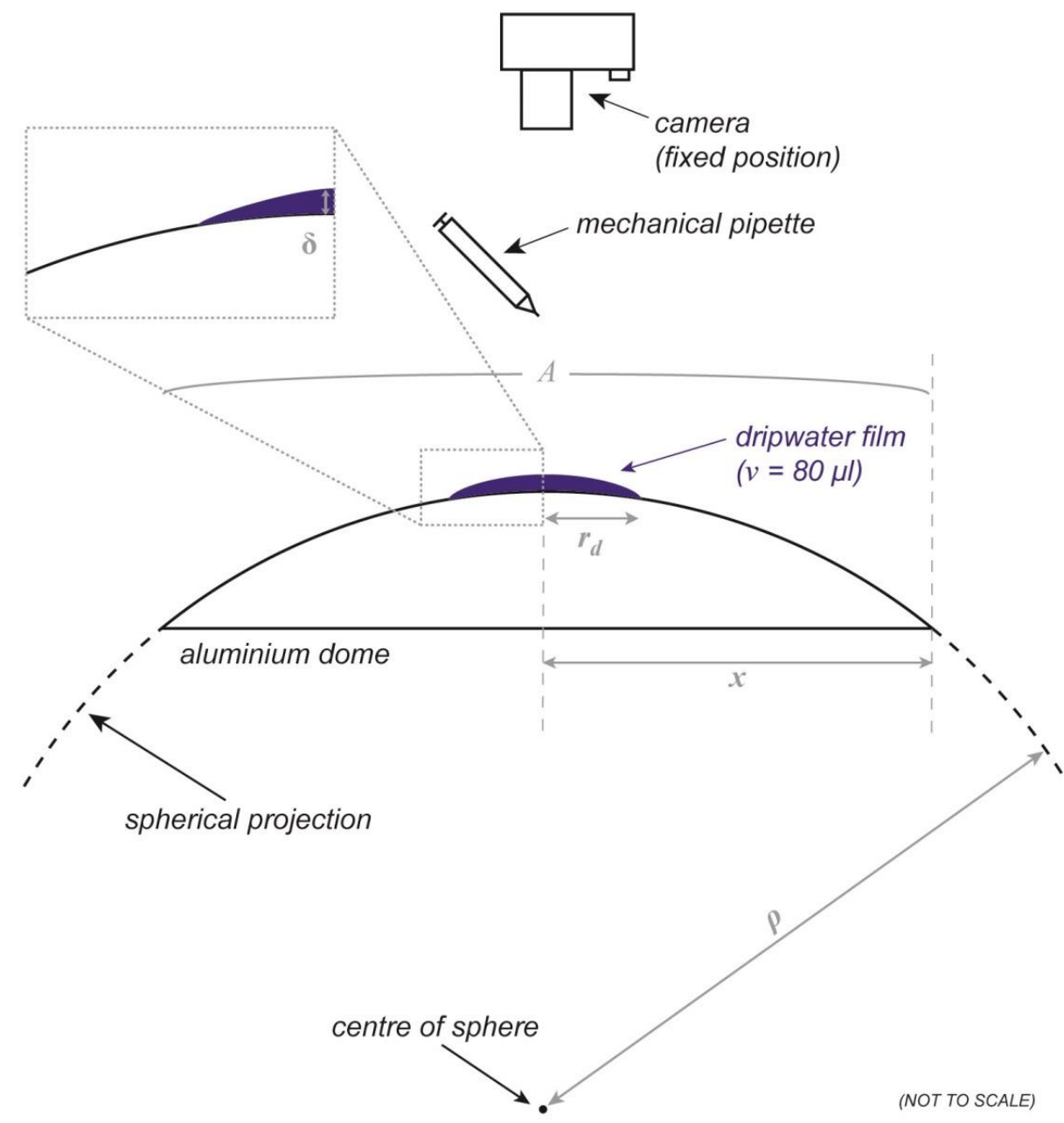

Figure S1. Illustration of the experimental procedure for obtaining $\delta$ measurements from a fixed quantity of dyed water dispensed onto a wetted, curved Al surface. Terms are defined by Eq. 2 and Eq. 3. Note that figure is not to scale and that the morphology of the dripwater film in section view is also schematic. 


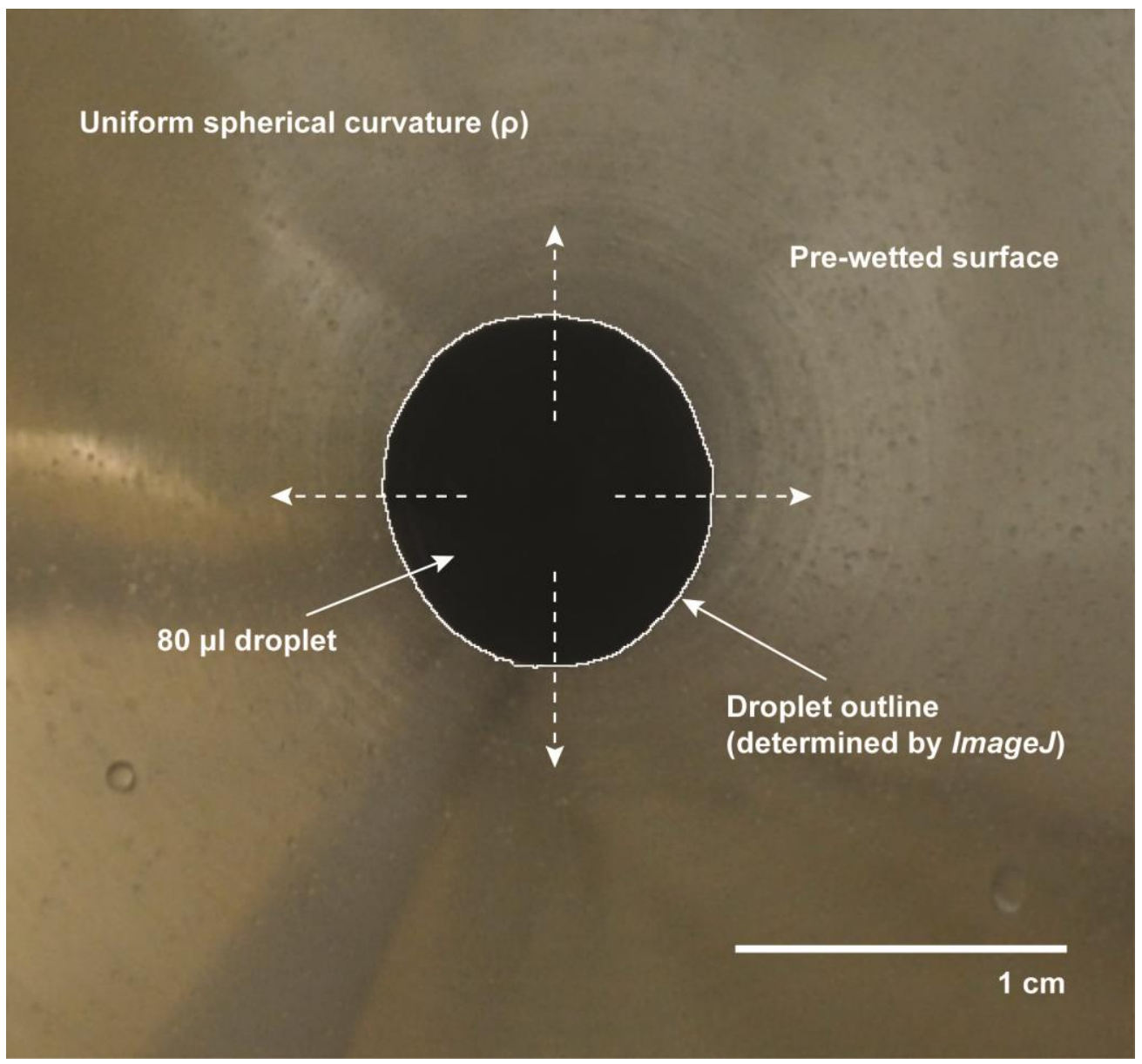

Figure S2. Top-view example photograph of a curved wetted aluminium surface with $80 \mu 1$ dyed water droplet dispensed onto its apex. The droplet spreads, indicated by the dashed arrows, over the uniformly curved surface $(\rho=37.5 \mathrm{~mm}$ in this image). The outline of the water film (solid white line), as determined by ImageJ, is accurate. Spreading does not necessarily displace existing water from pre-wetting the surface. Note that the image shows only the central area of the dome's surface; the width of this dome, $2 x$, is equal to $90 \mathrm{~mm}$ (Fig. 2). 


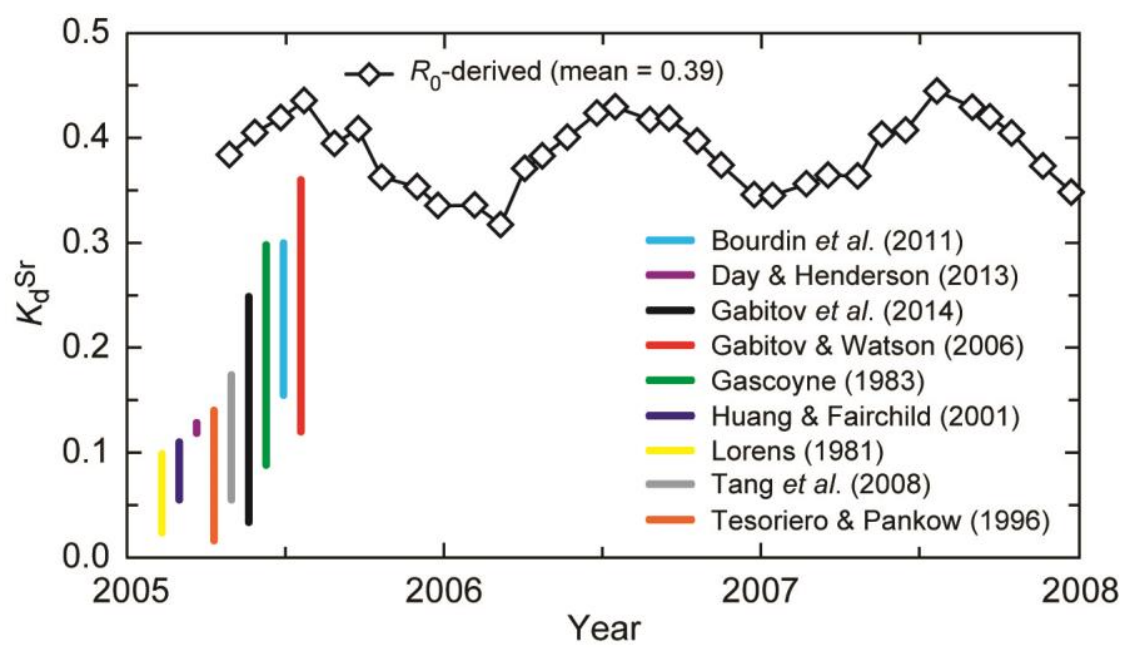

Figure S3. $\mathrm{K}_{\mathrm{d}}^{\mathrm{Sr}}$ time series derived from an extrapolation of the Gib04a $R_{0}$ reconstruction beyond the sampling date and into the cave monitoring period (diamonds). The mean $\mathrm{K}_{\mathrm{d}}^{\mathrm{Sr}}$ value of 0.39 is higher than but close to the range described by published data (coloured bars; not plotted against X-axis) (Bourdin et al., 2011; Day and Henderson, 2013; Gabitov et al., 2014; Gabitov and Watson, 2006; Gascoyne, 1983; Huang and Fairchild, 2001; Lorens, 1981; Tang et al., 2008; Tesoriero and Pankow, 1996). 


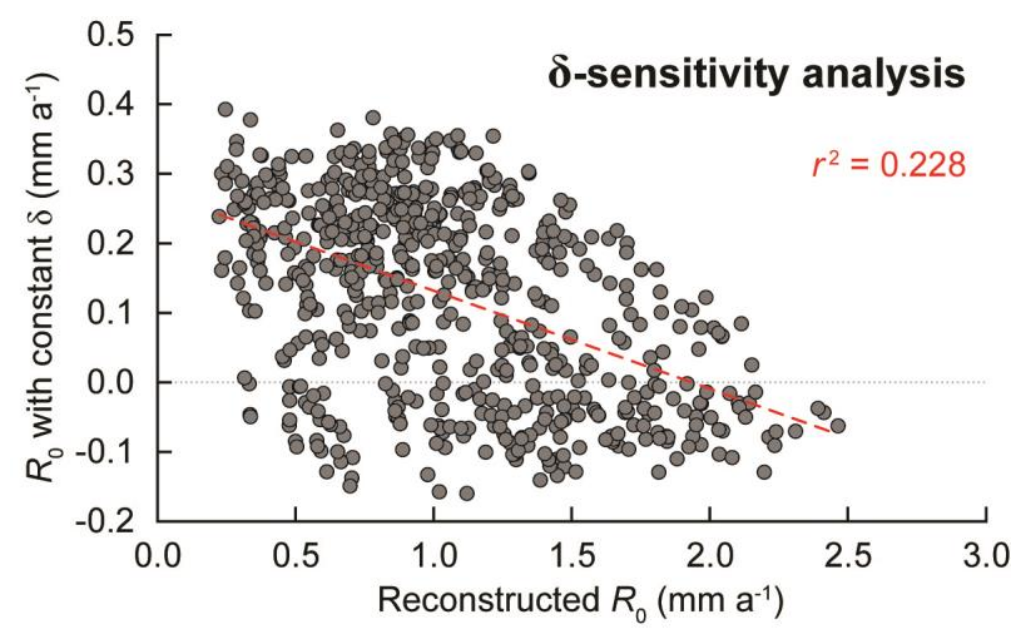

Figure S4. Quantification of $\delta$-sensitivity of Gib04a $R_{0}$. Values recalculated with constant $\delta$ and $\alpha$ (y-axis) versus original $R_{0}$ reconstruction as per Fig. 6 (x-axis). Linear regression between these two datasets gives $r^{2}=0.23\left(p=1.04 \times 10^{-43} ; n=684\right)$. 